Document downloaded from:

http://hdl.handle.net/10251/78882

This paper must be cited as:

Campo García, ADD.; Gualberto Fernandes, TJ.; Molina Herrera, A. (2014). Hydrologyoriented (adaptive) silviculture in a semiarid pine plantation: How much can be modified the water cycle through forest management?. European Journal of Forest Research. 133(55):879-894. doi:10.1007//s10342-014-0805-7.

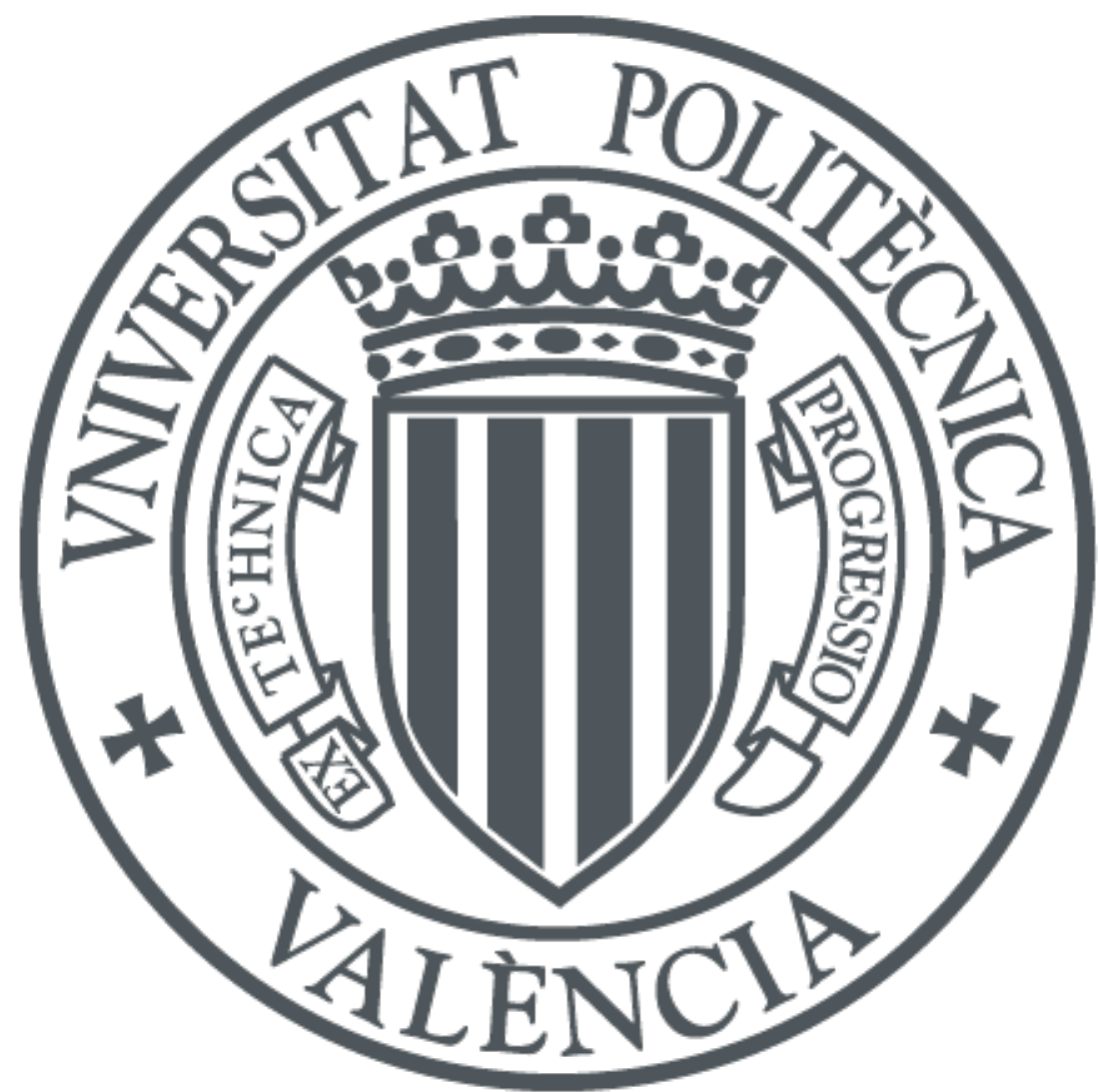

The final publication is available at

http://dx.doi.org/10.1007/s10342-014-0805-7

Copyright Springer Verlag (Germany)

Additional Information 


\section{European Journal of Forest Research \\ Hydrology-oriented (adaptive) silviculture in a semiarid pine plantation: how much can be modified the water cycle through forest management? --Manuscript Draft--}

\begin{tabular}{|c|c|}
\hline \multicolumn{2}{|l|}{ Manuscript Number: } \\
\hline Full Title: & $\begin{array}{l}\text { Hydrology-oriented (adaptive) silviculture in a semiarid pine plantation: how much can } \\
\text { be modified the water cycle through forest management? }\end{array}$ \\
\hline Article Type: & Original Research Paper \\
\hline Keywords: & $\begin{array}{l}\text { Forest hydrology; dendrochronology; Pinus halepensis; transpiration; blue-green } \\
\text { water }\end{array}$ \\
\hline Corresponding Author: & $\begin{array}{l}\text { Antonio D del Campo, Ph.D. } \\
\text { Polytechnic University of Valencia } \\
\text { SPAIN }\end{array}$ \\
\hline \multicolumn{2}{|l|}{$\begin{array}{l}\text { Corresponding Author Secondary } \\
\text { Information: }\end{array}$} \\
\hline Corresponding Author's Institution: & Polytechnic University of Valencia \\
\hline \multicolumn{2}{|l|}{$\begin{array}{l}\text { Corresponding Author's Secondary } \\
\text { Institution: }\end{array}$} \\
\hline First Author: & Antonio D del Campo, Ph.D. \\
\hline \multicolumn{2}{|l|}{ First Author Secondary Information: } \\
\hline \multirow[t]{3}{*}{ Order of Authors: } & Antonio D del Campo, Ph.D. \\
\hline & Tarcisio José Gualberto Fernandes, MSc. \\
\hline & Antonio J. Molina, MSc. \\
\hline \multicolumn{2}{|c|}{ Order of Authors Secondary Information: } \\
\hline Abstract: & $\begin{array}{l}\text { Hydrology-oriented silviculture might adapt Mediterranean forests to climatic changes, } \\
\text { although its implementation demands a better understanding and quantification on the } \\
\text { water fluxes. The influence of thinning intensity (high, medium, low and a control) and } \\
\text { its effect on the mid-term (thinned plots in } 1998 \text { and 2008) on the water cycle } \\
\text { (transpiration, soil water and interception) and growth (Basal Area Increment, BAI) } \\
\text { were investigated in } 55 \text {-year-old Aleppo pine trees. Thinning enhanced a lower } \\
\text { dependence of growth on climate fluctuations. The high intensity treatment showed } \\
\text { significant increases in the mean annual BAI (from } 4.1 \text { to } 17.3 \mathrm{~cm} 2 \text { ) that were } \\
\text { maintained in the mid-term. Thinning intensity progressively increased the sap flow } \\
\text { velocity (vs) in all cases with respect the control. In the mid-term, an increased } \\
\text { functionality of the inner sapwood was also observed. Mean daily tree water use } \\
\text { ranged from } 5 \text { (control) to } 18 \text { (high intensity) I tree- } 1 \text {. However, when expressed on an } \\
\text { area basis, daily transpiration ranged from } 0.18 \text { (medium) to } 0.30 \text { mm (control), } \\
\text { meaning that, in spite of the higher transpiration rates in the remaining trees, stand } \\
\text { transpiration was reduced with thinning. Deep infiltration of water was also enhanced } \\
\text { with thinning (about } 30 \% \text { of rainfall) and did no compete with transpiration, as both } \\
\text { presented opposite seasonal patterns. The changes in the stand water relationships } \\
\text { after ten years were well explained by the forest cover metric. The blue to green water } \\
\text { ratio changed from } 0.15 \text { in the control to } 0.72 \text { in the high intensity treatment, with the } \\
\text { remaining treatments in the } 0.34-0.48 \text { range }\end{array}$ \\
\hline \multirow[t]{2}{*}{ Suggested Reviewers: } & $\begin{array}{l}\text { Eugene Ungar } \\
\text { eugene@volcani.agri.gov.il } \\
\text { Very close research recently published in FORECO }\end{array}$ \\
\hline & $\begin{array}{l}\text { Michael Bredemeier } \\
\text { mbredem@gwdg.de } \\
\text { editor of the Ecological studies monograph \#212, closely related to the research topic } \\
\text { of the manuscript }\end{array}$ \\
\hline
\end{tabular}




\title{
Hydrology-oriented (adaptive) silviculture in a semiarid pine plantation: how much can be modified the water cycle through forest management?
}

\author{
Antonio D. del Campo ${ }^{1 *}$, Tarcísio J. G. Fernandes ${ }^{1,2}$, Antonio J. Molina ${ }^{3}$, \\ ${ }^{1}$ Research Group in Forest Science and Technology (Re-ForeST). Universitat \\ Politècnica de València. Camí de Vera s/n. 46022 Valencia (Spain) \\ ${ }^{2}$ Permanent address at the Center of Science Biology and Nature, Federal University of \\ Acre, BR 364, Km 04, CEP 69.915-900, Rio Branco, Acre (Brazil) \\ ${ }^{3}$ Research and Technology Food and Agriculture (IRTA). Torre Marimon, 08140 \\ Caldes de Montbui (Spain) \\ * Corresponding Author: ancamga@upv.es
}

Phone: (+34) 963877966

Fax: $(+34) 963877618$

\begin{abstract}
Hydrology-oriented silviculture might adapt Mediterranean forests to climatic changes, although its implementation demands a better understanding and quantification on the water fluxes. The influence of thinning intensity (high, medium, low and a control) and its effect on the mid-term (thinned plots in 1998 and 2008) on the water cycle (transpiration, soil water and interception) and growth (Basal Area Increment, BAI) were investigated in 55-year-old Aleppo pine trees. Thinning enhanced a lower dependence of growth on climate fluctuations. The high intensity treatment showed significant increases in the mean annual BAI (from 4.1 to $17.3 \mathrm{~cm}^{2}$ ) that were maintained in the mid-term. Thinning intensity progressively increased the sap flow
\end{abstract}


velocity $\left(v_{s}\right)$ in all cases with respect the control. In the mid-term, an increased functionality of the inner sapwood was also observed. Mean daily tree water use ranged from 5 (control) to 18 (high intensity) 1 tree $^{-1}$. However, when expressed on an area basis, daily transpiration ranged from 0.18 (medium) to $0.30 \mathrm{~mm}$ (control), meaning that, in spite of the higher transpiration rates in the remaining trees, stand transpiration was reduced with thinning. Deep infiltration of water was also enhanced with thinning (about $30 \%$ of rainfall) and did no compete with transpiration, as both presented opposite seasonal patterns. The changes in the stand water relationships after ten years were well explained by the forest cover metric. The blue to green water ratio changed from 0.15 in the control to 0.72 in the high intensity treatment, with the remaining treatments in the $0.34-0.48$ range.

\section{Key words:}

Forest hydrology, dendrochronology, Pinus halepensis, transpiration, blue-green water.

\section{Introduction and objectives}

Pine reforestation of barren lands has been called as an appropriate technique for soil and water conservation in the Mediterranean region, in which millions of hectares have been reforested, especially in Spain and Turkey (FAO 2010). Most of the plantations were established with one or several pine species (Pinus halepensis, $P$. pinaster, $P$. pinea) due to their excellent performance under harsh climatic and edaphic conditions. The improvement in site conditions (microclimate and soil properties) brought by the pine forests is expected to trigger late-successional species to spontaneously establish and to stimulate the ecosystem towards a more mature stage. However, this has not been the case in many semiarid areas, where additional management is needed to promote 
stand dynamics (Sánchez-Salguero et al. 2010). Thinning, the introduction of resprouting shrubs or the integration of small-scale spatial heterogeneity into the stand management strategy might be adequate techniques to improve stand resilience and overcome decline or stand stagnation (Maestre and Cortina 2004; Molina and del Campo 2012).

Under a general scope of precipitation decrease and evapotranspiration increase due to climate change in the Mediterranean, proactive adaptive management is becoming a basic strategy to either maintain or to gradually adapt current forest ecosystems (Birot and Gracia 2011; Fitzgerald et al. 2013; Lidner et al. 2010). Artificial plantations are a special case of forests with low resilience to environmental shifts, and they could be really favoured from this adaptive silviculture (Ungar et al. 2013). However, this type of silviculture is underdeveloped in many aspects as compared to that traditionally oriented to timber production. In this sense, guidelines dealing on how to maintain site productivity, enhance soil water content or promote tree and stand resilience (most adapted species, proper density, etc.) are needed for specific regions or ecosystem types. The long-term effect of forest management on the water cycle has been a topic deeply studied in the field of forest hydrology by comparing the water flux in the catchment outlet (Webb et al. 2012). These types of studies are very useful to know the global impacts of forest management at catchment scale. However, land uses in Mediterranean catchments are very heterogeneous and the forest management should consider it accordingly. In this sense, there is still a need for an improved understanding of how the different elements of the water cycle are affected and what is the management margin that foresters have to manipulate these elements (del Campo 2013). That is to say, it is needed to develop guidelines for a more efficient implementation of hydrology-oriented silviculture, which pursuits the quantification and the manipulation of water cycle 
components in forests according to management objectives (Molina and del Campo 2012). The terms blue and green water (Falkenmark 2003) are usually referred to in this context (Birot et al. 2011).

Several studies conducted in the Mediterranean region have focused on the short-term effects of thinning on tree-water use and have demonstrated an increment in throughfall, an improvement of conditions for tree growth and a reduction of the evapotranspiration (Aussenac 2000; Ganatsios et al. 2010; Molina and del Campo 2012). Previous studies have addressed the water balance in Aleppo pine plantations in the eastern Mediterranean (Schiller and Cohen 1998; Ungar et al. 2013). However, understanding how and how much the water fluxes are mutually affected as a function of the intensity of the treatments, or how and how much their mid-term effect is offset by densification and expansion of the canopy and root systems (Aussenac and Granier 1988; Andréassian 2004; Delzon and Loustau 2005) remains unclear. The aim of this paper is to study how the water balance and the tree growth change as a consequence of thinning. Previous results on the effect of thinning intensity on the throughfall and stemflow were reported in Molina and del Campo (2012). Two main aspects are dealt with in this work, firstly the influence of thinning intensity and secondly the effect of the elapsed time since thinning. The experimental hypothesis is, in the first case, that clearing more trees increases the ratio of blue to green water (decreases the evapotranspiration's components), whereas in the second case, this ratio decreases with the time elapsed since thinning. To address these questions five experimental plots were established, three of them were thinned in 2008 at different intensities, the forth was thinned in 1998 and the fifth was a control. Specific questions to be addressed are: i) what is the effect of the thinning intensity and the effect of the elapsed time since thinning on tree transpiration, soil water and growth? ii) How are 
affected the throughfall and stemflow by the time elapsed since the thinning intervention? iii) How does the global water balance of the forest change with both the thinning intensity and the elapsed time since thinning?

\section{Materials and methods}

\subsection{Study site and experimental trial}

The study was carried out in a planted pine forest located in the southwest region of Valencia province in Spain $\left(39^{\circ} 05^{\prime} 30^{\prime \prime} \mathrm{N}, 1^{\circ} 12^{\prime} 30^{\prime \prime} \mathrm{W}\right)$ at $950 \mathrm{~m}$ a.s.l. The average annual rainfall is $465.7 \mathrm{~mm}$ and typically shows high intra- and inter-annual variability. The mean annual temperature is $13.7^{\circ} \mathrm{C}$, the mean annual potential evapotranspiration is $749 \mathrm{~mm}$ (Thornthwaite), and the reference evapotranspiration is $1200 \mathrm{~mm}$ (Hargreaves). The soils display a basic $\mathrm{pH}$ of 7.6, are relatively shallow $(50-60 \mathrm{~cm})$ and have a sandy-silty loam texture.

The $P$. halepensis plantations were established in the area during the late 1940 s with high densities (approximately 1500 trees $\mathrm{ha}^{-1}$ ), and no forest management has been carried out due to the role of the forest in soil protection (corroborated by the personnel at the nearby forest nursery). In late 1998, a 100 meters-wide strip thinning was performed in order to break the continuity of the forest canopy, as a typical fire prevention practice. This high intensity thinning (H98) left a final stand density of 155 trees $\mathrm{ha}^{-1}$ and cover of $41 \%$ in 2009 . In this area the understory vegetation is removed every two to three years. In February 2008, a new experimental thinning including several intensities was carried out in the vicinity of the H98 treatment $(80 \mathrm{~m})$. In this case, each thinning treatment was performed in an experimental plot of $30 \times 30 \mathrm{~m}$. One plot was not thinned (control, C) and the other plots were thinned at three different intensities: high $(\mathrm{H})$, medium $(\mathrm{M})$ and low $(\mathrm{L})$. Thinning removed the less developed 
trees and was performed to achieve a relatively homogeneous tree distribution (based on forest cover) in the plots. Thinning was conducted and supervised by the Forest Service of Valencia; timber and debris were removed and piled outside the plots. All plots were on a slope of less than $5 \%$. Forest structure characterization in all plots was accomplished in March 2009 as indicated in Molina and del Campo (2012) and presented in Table 1.

\subsection{Tree selection and characterisation}

A total of 20 trees (four per plot) were selected to study growth and transpiration by considering a diameter distribution of 3 classes in each plot. Two trees were selected from the lowest and the highest diameter class respectively, and the other two were selected from the middle class. This sample, although modestly sized, falls within the range considered in tree water-relations studies (Granier 1987; Klein et al. 2013; Martínez-Vilalta et al. 2002). Trees were selected from both the 2008 thinning (C, L, $\mathrm{M}$ and $\mathrm{H}$ ) and the 1998 thinning (H98). The effect of forest management intensity was studied in the 2008 plots, whereas the influence of time elapsed since thinning was studied in both high intensity plots (1998 and 2008) assuming a chronosequence (Major 1951), i.e., regional climate, parent material (soil origin), topography and biota were considered as constant between both plots, whereas time was considered as variable. In this case, although both plots were the same age, we assumed both are two different temporal stages of the same population. In these treatments, characterization of trees was additionally performed, as these should have different architecture (Table 1): total height was measured with an optical hypsometer (Suunto, Finland), crown diameter was calculated by averaging the measurements of two orthogonal crown diameter projections, crown volume was estimated after summing up the two volumes (the lower 
third as a cylinder and the other two thirds as a pyramid), and bark thickness was estimated by averaging two measurements from the north and south sites of the trunks.

\subsection{Tree growth}

Tree growth was studied using dendrochronological procedures. Two cores (north and south) were extracted from each selected tree at the end of the study (5-mm increment core). To avoid under-estimation (Mérian et al. 2013), between four and eight additional trees per plot were cored in the same way. All cores were visually cross-dated and measured to the nearest $0.01 \mathrm{~mm}$ (LINTAB 6.0, coupled with the TSAP-Win software package). Cross-dating of the tree-ring series was evaluated using COFECHA software (Holmes 1983). Basal Area Increment (BAI) was selected as an indicator of growth because it is closely related to the sapwood area and was calculated both per year and per tree. The BAI series were standardised by dividing the raw BAI by the expected values (dimensionless index) using a double de-trending method: first, the series were adjusted by a negative exponential curve or a linear regression, second, a cubic smoothing spline function was used with a wavelength fixed at $66 \%$ of the length of the series and a 50\% frequency cut-off; third, autoregressive modelling was carried out on each series to remove temporal autocorrelations (Cook and Briffa, 1990). The indexed residual series were subsequently averaged using a bi-weighted robust mean to obtain the residual chronologies using the dplR R-package (Bunn 2008; R Core Team 2013). The result of this procedure was a Basal Area Increment Index (BAIi).

\subsection{Transpiration and tree-water use determinations}

The study of the water cycle spans the period from March $27^{\text {th }} 2009$ to May $31^{\text {st }} 2011$, when most of the measurements were available, giving a total of 796 days, or 25 months, or 2.08 years. However, other time spells are included as seen in next points. Sap flow velocity was measured through the HRM method (Burgess et al. 2001) in all 
sample trees and programmed to average every hour. One sap flow sensor (HRM sensor, ICT International, Australia) was installed in each selected tree on the north side of the trunk at a $1.3-\mathrm{m}$ height. A heater emits the heat pulse, and the temperature increase is subsequently measured in two needles containing two thermocouples each, located $27.5 \mathrm{~mm}$ and $12.5 \mathrm{~mm}$ from their bases. Each pair of measurements (inner and outer) is after used to estimate the heat pulse velocity at the both depths and converted to sap flow velocity, $v_{s}$ (Burgess et al., 2001). The system was powered by a $12-\mathrm{V}$ battery connected to a solar panel and a data-logger (Smart Logger, ICT). Sapwood area was obtained by subtracting heartwood area from the inner-bark area (Giuggiola et al. 2013) from the cores extracted for the growth analysis. The sapwood area was divided into four different sections to assign different $v_{s}$ values and consequently to estimate daily values of sap flow $\left(1\right.$ day $\left.^{-1}\right)$ (Hatton et al. 1990; Delzon et al. 2004) as the sum of their multiplications: 1) the $v_{s}$ from the outer thermocouple was assigned to the sapwood area from the cambium to middle point located between the outer and inner thermocouples (i.e., 20-mm depth); 2) the $v_{s}$ from the inner thermocouple was assigned to the sapwood area from the middle point to inner depth of the sensor $(27.5-\mathrm{mm}$ depth from the cambium); and 3,4) the remaining area from the inner depth to the beginning of the heartwood or to the pith (if heartwood was not present) was divided into two halves and then, the $v_{s}$ value from the inner thermocouple was multiplied by 0.75 and 0.25 respectively. Sap flow was up-scaled by the number of trees (density) to get the stand transpiration ( $\mathrm{mm}$ ) taking into account the diameter frequency distribution of trees in the different treatments.

Data were quality controlled for any possible spikes and gaps. In some cases, sap flow data were lost for more than 15-day spells (several months in the case of the M treatment), because of datalogger/sensors malfunction, battery failure and rodents 
activity. In these cases, an Artificial Neural Network (ANN) model was used to estimate transpiration (mm) using cover forest, soil moisture and meteorological data (coefficient of correlation: 0.95; Nash-Sutcliffe coefficient: 0.90).

\subsection{Soil water content and climate variables}

The soil water content ( $\mathrm{SWC}, \mathrm{m}^{3} \mathrm{~m}^{-3}$ ) was continuously measured for the whole period in all treatments every 20 minutes by means of FDR sensors (EC-TM, Decagon Devices Inc., Pullman, WA) connected to several EM50 (Decagon) data-loggers. In each treatment, between 6 and 9 sensors were placed at a $30 \mathrm{~cm}$ depth considering either tree influence or not (under projected crown or not). Field calibrations were carried out by determining the gravimetric water content in 4 sampling dates (saturation, field capacity, between field capacity and wilting point and wilting point) to obtain the full range of soil water content in the study site. After the data readings were corrected, the current volumetric water content was divided by soil water content at field capacity (SWC/FC), in order to have a relative variable to be used in the comparisons among the treatments. Field capacity in each treatment was calculated from the average of SWC's readings in three dates $(28-29 / \mathrm{March} / 09 ; 12 / \mathrm{Oct} / 10 ; 23 / \mathrm{March} / 11)$ in which the rainfall depth was higher than $30 \mathrm{~mm}$ in the previous two days. These dates were selected in cool days (see next point). Data gaps in SWC for a whole treatment were minimal due to the use of several sensors and data-loggers, which always allowed for reliable data. However, in the medium treatment the number of data gaps was higher and estimations were performed from linear or polynomial functions fitted with the neighbouring sensors $\left(r^{2}>0.80\right)$.

The rainfall (Gr) was continuously measured by means of a tipping-bucket rain gauge with $0.2-\mathrm{mm}$ resolution (7852 Davis, USA) located in an open area at $400 \mathrm{~m}$ apart from 
the experimental plots. Measurements of air temperature and relative humidity were collected by a single sensor (RH/T sensor, Decagon Devices, Pullman, USA) placed at a $1 \mathrm{~m}$ height close to the rainfall gauge. The data were subsequently used to obtain values for the vapour pressure deficit.

\subsection{Throughfall and stemflow on a tree basis ( $H$ and $H 98$ treatments)}

A previous study (Molina and del Campo 2012) addressed the influence of thinning intensity on throughfall and stemflow in this site. The influence of time elapsed since thinning on the rainfall the partitioning was studied here on a tree basis, i.e., under the crowns of the $\mathrm{H}$ and $\mathrm{H} 98$ trees. The throughfall was measured under the crownprojected area of each sample tree by a set of 18 collectors $(\varnothing: 12 \mathrm{~cm})$ systematically placed on six radial axes $\left(60^{\circ}\right)$ with respect to the trunk ( 72 collectors per treatment), at a $50 \mathrm{~cm}$ height and separated $50 \mathrm{~cm}$ from each other. The data collection was conducted between November 2009 and February 2010, the main rainy season in the area, by gauging the collectors 1 to 3 days after. Evaporation during rainfall was expected to be negligible and very similar among isolated trees of different structure (Pereira et al. 2009). Therefore, the collectors' measurements (throughfall) were assumed to be representative of the water saturation capacity of crown. The stemflow was initially measured in the same season, although the low amount of stemflow and its irregularity made it advisable to extend the measuring until June 2010. This variable was measured in all sample trees by fixing plastic collars (cut lengthwise) to the trunks at a $1.3-\mathrm{m}$ height. Water from the collars was subsequently collected in 10-1 tightly closed containers at intervals of 6-12 days.

\subsection{Data analysis}


The total set of 796 days was divided into four day-types according to daily precipitation and daily mean temperature. First, days were grouped into dry or wet spells (D, W). A dry spell was considered to begin when none of the previous 14 consecutive days registered a daily precipitation higher than $5 \mathrm{~mm}$ (day $14^{\text {th }}$ would belong to wet and day $15^{\text {th }}$ would belong to dry; that is to say, wet spell is set to a minimum to 14 days long, whereas dry spells do not have minimum limit). This resulted in 18 and 17 wet and dry spells respectively. Secondly, in any of these periods, each single day was classified as cool or warm $(\mathrm{C}, \mathrm{W})$ if its mean temperature was respectively lower or higher than $13.2^{\circ} \mathrm{C}$, the overall mean of the data set. The $\mathrm{DC}, \mathrm{DW}$, WC and WW codes are used for each day-type.

Differences in BAIi, $v_{s}$, sap flow and $\mathrm{SWC} / \mathrm{FC}$ among treatments were analysed with ANOVA (Steel and Torrie 1989) with treatment and tree considered as fixed factors. When ANOVA indicated significant differences between treatments, the Tukey posthoc test was selected for the comparison of multiple means. In every case, the data were examined to ensure normality using the Kolmogorov-Smirnoff test and the homogeneity of variance using the Levene test. When these assumptions were violated, the variables were transformed with power functions to achieve homoscedasticity or, alternatively, a nonparametric Kruskal-Wallis test was used (with the Tamhane's T2 test used to compare multiple means). Relationships between different variables (growth and transpiration) were investigated through Pearson correlations and linear regression models. Here, the residuals were examined for normality and independence (Steel and Torrie 1989). A significance level of $\mathrm{p}<0.05$ was used for all analyses. Data were analysed with SPSS $\subset$ 16.0. All statistical proofs were performed considering only empirical data, i.e. data estimated to fill in gaps were used exclusively for water 
balances. In the case of $v_{s}$, sap flow and SWC/FC the analyses were also carried out for the four different day-types.

\section{Results}

\subsection{Climatic conditions during the study period}

From April 2009 to May 2011 the total precipitation was $1545 \mathrm{~mm}, 511 \mathrm{~mm}$ higher than expected (1961-2007). Despite this observation, drought spells occurred throughout the study period: only $26 \mathrm{~mm}$ rained in the 17 dry spells registered, accounting for 210 days out of the 796 days. The longest dry spell lasted 48 days (summer 2009). From December 2009 to April 2010, precipitation was much higher than expected. Regarding temperature, 412 days were classified as cool days $\left(\mathrm{T}<13.2^{\circ} \mathrm{C}\right)$ and 383 days as warm $\left(\mathrm{T}>13.2^{\circ} \mathrm{C}\right)$ (Fig. 1). Mean vapour pressure deficit (VPD) for each category was $0.37 \pm 0.17,1.56 \pm 0.73,0.26 \pm 0.17,0.96 \pm 0.57 \mathrm{kPa}$ for $\mathrm{DC}, \mathrm{DW}, \mathrm{WC}$ and $\mathrm{WW}$ respectively. Frequency of each day-type in the whole study period is presented in Table 2.

\subsection{Tree Growth}

The BAI and BAI index (BAIi) series showed similar patterns until thinning both for the intensity $(\mathrm{C}, \mathrm{L}, \mathrm{M}, \mathrm{H})$ and the elapsed time (H, H98) treatments (Figs. 2 and 3) with significant correlations between any pair of treatments in all cases (Pearson correlation p-value $<0.001,1960-1997$ series). This similar pattern changed sharply in response to the thinning treatments carried out either in 1998 (case of elapsed time) or in 2008 (case of thinning intensity) and no significant correlation (neither for BAI and BAIi) was detected from this time onwards. In the intensity treatments, the BAI changed from an annual mean of $4.09 \pm 1.36$ and $3.61 \pm 1.19 \mathrm{~cm}^{2}(1960-2007)$ in $\mathrm{H}$ and $\mathrm{C}$ treatments respectively to an annual mean of $17.29 \pm 5.96$ and $3.47 \pm 0.14 \mathrm{~cm}^{2}(2008-2010)$ 
respectively. $\mathrm{L}$ and $\mathrm{M}$ thinning treatments presented intermediate values $(5.18 \pm 0.39$ and $7.23 \pm 2.07 \mathrm{~cm}^{2}$ in the $2008-2010$ spell respectively) (Fig. 2). In the case of H98, the BAI increased from an annual mean of $3.52 \pm 1.03 \mathrm{~cm}^{2}$ in $1960-1997$ to $18.31 \pm 8.92 \mathrm{~cm}^{2}$ in 1998-2010 (Fig. 2).

Parametric tests indicated significant differences in the BAIi after thinning treatments, either for the intensity or the elapsed time factors ( $p$-value $<0.001$ ). In the former case, $C$ and $\mathrm{L}$ presented BAIi values significantly lower than those of $\mathrm{M}$ and $\mathrm{H}$ treatments, whereas in the latter case, BAIi in H98 was significantly lower in the period 1998-2010 than that for $\mathrm{H}$ in the period $2008-2010$ (1.03 \pm 0.45 and $1.48 \pm 0.13$ respectively). Another remarkable result was that, independently of the treatments, the BAIi chronology (Fig. 2) reflected a first stage with low amplitude oscillations until the early 1980s and a second stage from this date onwards in which the amplitude of the oscillations was higher: most of the values (89\%) falling outside of the central interval (10\%-90\%) belong to years after 1980 (57\% of the years). This observation was especially relevant in the driest years (e.g., 1988, 1995 and 2005), which induced a sharp decrease in growth.

\subsection{Tree-water use and stand transpiration}

The water use data showed a variable behaviour depending on the different factors being considered in this study: the variable considered (i.e., $v_{s}$ [mean, outer, inner], sap flow or stand transpiration), type of analysis (thinning intensity or elapsed time), or the day-type (spells) (Table 2; Fig. 4;). Thinning intensity affected significantly $v_{s}$ both on its outer and inner measurements, progressively increasing with the intensity of the treatment from $\mathrm{C}$ to $\mathrm{H}$ (Table 2). Moreover $v_{s}$ (mean) was also significantly affected by thinning intensity according to the day-type considered, with warm days (either from wet or dry spells) associated to higher differences among treatments (Table 2). The 
maximum differences among treatments were found when $v_{s}$ (mean) was high, where the Tukey test yielded four single-treatment groups. Sap flow differences among treatments were also significant, with higher differentiation in the warm spells too. Tukey tests always isolated the $\mathrm{H}$ treatment from the others, whereas $\mathrm{C}$ and $\mathrm{L}$ were frequently joined in a same group; $M$ treatment showed an intermediate pattern between the $\mathrm{L}$ and $\mathrm{H}$ treatments in most of the cases (Table 2). In several trees from the $\mathrm{H}$ treatment, daily sap flow in June and July 2009 (dry warm spell) surpassed the amount of 501 .

Regarding the elapsed time from thinning, the $v_{s}$ was significantly different between $\mathrm{H}$ and H98 in all analyses, with the latter showing values about one half of $\mathrm{H}$, except in the inner sapwood $v_{s}$, where differences were lower (Table 2). In this comparison, the sap flow $\left(1\right.$ day $^{-1}$ tree $\left.^{-1}\right)$ presented significant differences between both treatments only in the warm spells and the magnitude of these differences was lower (about one third), thus indicating relatively less changes in total tree-water consumption after ten years of thinning intervention. The weighted (from each day-type frequency) daily average of sap flow during the study period was 5.22, 5.08, 8.52, 17.77 and 14.39 litres of water transpired per tree for treatments $\mathrm{C}, \mathrm{L}, \mathrm{M}, \mathrm{H}$ and $\mathrm{H} 98$ respectively. Considering the frequency distribution of diameters in the different treatments as well as the tree density (Table 1), the previous sap flow values correspond to $0.297,0.256$, $0.180,0.271$ and $0.170 \mathrm{~mm}$ transpired per day or $108.6,93.4,65.7,98.9$ and $61.9 \mathrm{~mm}$ transpired per year for treatments $\mathrm{C}, \mathrm{L}, \mathrm{M}, \mathrm{H}$ and $\mathrm{H} 98$ respectively. The tree growth (BAI) presented many significant correlations with $v_{s}$ and the sap flow (Table 3). Theses correlations were stronger $(p$-value $<0.001)$ when considering transpiration variables from the previous year, i.e., the 2010 BAI with the 2009 transpiration variables. Also, the association was higher for warmer periods, with 
Pearson's coefficient reaching values higher than 0.8 . The BAIi showed few significant correlations with the transpiration variables and these were weaker than in the case of BAI ( $\mathrm{p}$-value $<0.05$ ). Based on those correlations, simple linear regressions between $v_{s}$ and BAI were developed. The models fitted were $\mathrm{v}_{\mathrm{s} \text { inner } 2009}=0.071 * \mathrm{BAI}_{2010}+0.5961$ $(\mathrm{p}<0.001, \mathrm{r}=0.70$, d.f.: $14 ; \mathrm{MAE}=0.44 ; \mathrm{MAPE}=52.9 \%)$ and $\mathrm{v}_{\mathrm{s} \text { outer } 2009}=0.098 * \mathrm{BAI}_{2010}$ $+0.9689(\mathrm{p}<0.001, \mathrm{r}=0.65$, d.f.: $14 ; \mathrm{MAE}=0.68 ; \mathrm{MAPE}=35.3 \%)$.

\subsection{Soil water content}

According to the calibration, the sensors output increased the estimated volumetric water content in a general manner. Soil water content at field capacity varied among treatments in spite of their vicinity: $0.306 \pm 0.026,0.264 \pm 0.016$, and $0.252 \pm 0.026$, $0.316 \pm 0.023$ and $0.201 \pm 0.025 \mathrm{~m}^{3} \mathrm{~m}^{-3}$ for $\mathrm{C}, \mathrm{L}, \mathrm{M}, \mathrm{H}$ and $\mathrm{H} 98$ respectively, thus showing a different water holding capacity. In this sense, comparisons among treatments were done based on the relative variable water content to field capacity ratio (SWC/FC) (Fig. 5).

Significant differences were obtained for either the thinning intensity analysis or the elapsed time analysis in the four day-types considered (Table 2). In the first case, the treatment $\mathrm{H}$ showed always more relative water content than $\mathrm{C}$ and $\mathrm{L}$ treatments (range $67-96 \%$ and $44-86 \%$ for $\mathrm{H}$ and $\mathrm{C}, \mathrm{L}$ respectively), whereas $\mathrm{M}$ had an intermediate behaviour, showing significant differences with $\mathrm{H}$ in the wet-cool spells (lower relative water content) and with $\mathrm{C}, \mathrm{L}$ in the dry spells (higher relative water content). Regarding the elapsed time analysis, differences between $\mathrm{H}$ and $\mathrm{H} 98$ were significant and maintained in the four day-types considered, showing the latter lower values.

\subsection{Throughfall and stemflow in the elapsed time analysis}


Throughfall in the thinning intensity analysis was presented in Molina and del Campo (2012). Regarding the elapsed time analysis, a total rainfall of $146.8 \mathrm{~mm}$ was collected during the rainy spells when throughfall was measured; spells ranged from 2.4 to 56.4 $\mathrm{mm}$. The throughfall under the crown-projected area of the sampled trees was always higher for treatment $\mathrm{H}$ (ranging from 55.2 to $77.0 \%$ of the gross rainfall) than for $\mathrm{H} 98$ (from 39.3 to $67.0 \%$ ) (Fig. 6). A significant difference (p-value $<0.001$; d.f.:142) was found between the total accumulated values of the throughfall in $\mathrm{H}(60.3 \pm 6.8 \%$ of the gross rainfall) and H98 (51.4 $\pm 9.7 \%$ of the gross rainfall), accounting for a mean general difference of $8.9 \%$. Linear regressions between the throughfall and the rainfall collected in each period were highly significant for both treatments (Throughfall $=0.64 *$ Gross_Rainfall- $0.75 ; \mathrm{p}<0.001, \mathrm{r}=0.97$, d.f.: $28 ; \mathrm{MAE}=1.17$; MAPE $=12.9 \%$, and Throughfall $=0.58 *$ Gross_Rainfall-1.57; $\mathrm{p}<0.001, \mathrm{r}=0.94$, d.f.: 27 ; $\mathrm{MAE}=1.79 ; \mathrm{MAPE}=36.7 \%$, for $\mathrm{H}$ and $\mathrm{H} 98$, respectively). The comparison between the models indicated that the intercepts were found to be different at $p$-value $<0.001$, whereas the slopes were not.

The stemflow showed a similar trend for both treatments, with no significant differences in the accumulated values for the entire study period, averaging $24.03 \pm 1.241$ tree $^{-1}$ in $\mathrm{H}$ and $17.73 \pm 9.451$ tree $^{-1}$ in H98 (Fig. 1. Electronic supplemental material). A high variation in stemflow was noted among the different periods as well as high intravariation in each treatment, an observation that was much more pronounced in treatment H98. The linear regressions showed a poor relationship between the stemflow and the rainfall in both treatments (not shown).

\subsection{Water balance for the whole study period}

An attempt of integration of previous results in a global water balance is presented in Table 4, which shows this balance for all the treatments on a stand basis (as mm and as 
$\%$ of rainfall). Stand interception (It) was subtracted to gross rainfall (mm) to compute total throughfall (stemflow was considered negligible). Interception was estimated on a daily basis based on the exponential model of throughfall reported in Molina and del Campo (2012). In the case of H98, the model was modified in order to decrease throughfall $0.82 \mathrm{~mm}$ under the area covered by the trees $(41 \%)$, as seen in this work. The remaining precipitation (net precipitation, Pn) was considered to be infiltration (I). Pn fallen when SWC/FC was higher or equal to 1 was considered as deep infiltration (Fig. 5), which is a proxy for deep percolation. Summing up the values per treatment, it yielded 207.6, 395.1, 455.5, 647.0 and $505.9 \mathrm{~mm}$ for C, L, M, H and H98 treatments respectively in the whole period analysed (796 days). These amounts were irregularly distributed among the four day-types: no deep infiltration was registered in the drywarm spells, negligible amounts in the dry-cool, between $14 \%(\mathrm{H})$ and $8.6 \%(\mathrm{C})$ of the total was infiltrated in the wet-warm periods and between $86 \%(\mathrm{H})$ and $91 \%(\mathrm{C}$ and $\mathrm{L})$ was infiltrated in the wet-cool periods.

Subtracting deep infiltration $\left(\mathrm{I}_{>30 \mathrm{~cm}}\right)$ to I corresponds to the Pn that fell when soil water content was below field capacity. This term was divided into stand transpiration $(\mathrm{T})$ and a residue that includes the upper soil horizon evaporation and the interception and transpiration of understory. The total evapotranspiration (interception plus stand transpiration plus the residual component) ranged from $86.6 \%$ of gross rainfall in the control treatment to $58.1 \%$ in the high intensity treatment $\mathrm{H}$, with the remaining treatments concentrated around the value of $70 \%$ (H98, M and L, from lower to higher evaporation). Concordantly, blue $\left(\mathrm{I}_{>30 \mathrm{~cm}}\right)$ to green (total evapotranspiration) water ratios ranged between $0.15(\mathrm{C})$ to $0.72(\mathrm{H})$. Time elapsed since thinning decreased this ratio to 0.49 , which is close to that of the medium intensity thinning, with similar forest cover. 


\section{Discussion}

Proactive adaptive silviculture is a key element for coping with the impacts of global change in the Mediterranean forests due to their higher vulnerability (Lindner et al. 2010). This brings into focus the need to develop, implement and improve adaptation measures. In the present study, the effect of thinning interventions was studied by focusing on the change in the distribution of water fluxes and tree growth in a planted pine forest in a semiarid climate.

\subsection{Tree growth}

The dendrochronological approach applied in this work facilitated the study of the stand growth during most of its lifespan. Growth was highly limited in the pre-thinning stages of the stand, with basal area showing increments around $3.5-4 \mathrm{~cm}^{2}$ year $^{-1}$. The BA increments for this species in the eastern region of Spain are within $8-11 \mathrm{~cm}^{2}$ year ${ }^{-1}$ for a DBH of 20-25 cm (Condés and Sterba 2008), although wider ranges (2-15 $\mathrm{cm}^{2}$ year $^{-1}$ ) and higher maximum values $\left(22.2 \mathrm{~cm}^{2}\right.$ year $^{-1}$ in the wettest area of the species in Spain) have also been reported (Sánchez-Salguero et al. 2010; Linares et al. 2011). In this study, the interventions improved the basal area increment in all cases, although in the low intensity thinning the value is still low as regards the reported ranges. On the contrary, the high intensity thinning treatments revealed the improved growth capacity of the species when competence is supressed. Delzon and Loustau (2005) showed that growth in a $P$. pinaster stand with 150 trees ha $^{-1}$ began to decline at approximately 40 years. In this work, the steady annual BAI in H98 of approximately $18 \mathrm{~cm}^{2}$ tree $^{-1}$ year from thinning on, indicates the potential and lasting response associated with thinning, even for the mature state of the studied trees (55 years old).

Tree ring chronologies reflect the complex interaction of climatic and environmental conditions at sites where samples are taken (Fritts 1976). In our case, the BAIi 
chronology reflected a two-stage pattern of oscillations, with a break point around the early 1980 s that was independent of the treatment. Water availability is one of the main factors that control growth in this species, with a significant relationship between tree growth and rainfall commonly observed (De Luis et al. 2009; Raventós et al. 2001; Sanchez-Salguero et al. 2010). In fact, in such semiarid well-drained sites as the experimental plots, a maximum response of the tree rings to precipitation is expected (Meko et al. 1995), and could be the driving factor for the higher amplitude of oscillations in the second stage of our chronology (from the early 1980s onwards). In this work, two observations occurred concurrently: first, the tree density became excessive in the early 1980s, necessitating at least one thinning intervention according to Montero et al (2001). Second, these years correspond to a generalised warming and drying trend in the Mediterranean climate, conditions that are reported to affect the growth of this species (Sarris et al. 2007, 2011; Linares et al. 2011). An increasing number of missing tree rings from the late 1980s has been reported in this species in a nearby area (Raventós et al. 2001). Long, intense and continuous droughts can have a spatial structuring effect on the growth index, especially if successive vegetative seasons record strong precipitation deficits (Planchon et al. 2008), as observed in 19941995 and 2004-2005 in this study. Fig 2 shows that the amplitude of oscillations is higher and the BAIi value is below 1 in $\mathrm{C} ; \mathrm{L}, \mathrm{M}$ and $\mathrm{H}$ in the last years before the thinning, but it changed to $1.08,1.22,1.39$ and 1.48 respectively for $2008-2010$. By the same, during the 1999-2007 spell, the H98 showed a trend towards values higher than 1, averaging 1.12. Taken together, these observations mean that a lack of forest management together with rainfall variability is highly reflected in the BAI index chronology, which shows a higher and stronger dependence of growth on climate fluctuations. 


\subsection{Tree water use and stand transpiration}

The tree water use results explain how the water fluxes have changed in the short and mid term after thinning. The availability of such limited resources such as water, radiation or nutrients has increased for the remaining trees, and as a consequence, tree water use has increased after thinning, which is a known fact (Medhurst et al. 2002; Morikawa et al. 1986). The results of tree water use have shown that differences in transpiration among the treatments varied depending on the considered variable, i.e., sap flow velocity $\left(v_{s}\right)$, sap flow or stand transpiration.

First, $v_{s}$ always increased with the intensity of the intervention, independently of the spells or the depth of the thermocouple (either inner or outer). This result might be due to an increase in the hydraulic conductivity of the sapwood soon after thinning (Medhurst et al. 2002), which might be also positively correlated with the increased water availability (White et al. 1998). The outer and inner $v_{s}$ data allow additional insight into the intrinsic differences between treatments in the sapwood functionality. We observed changes in the radial variation of $v_{s}$ with treatment and hence in the permeability of the sapwood: the mean differences between the outer and inner records went from $40 \%$ in the $\mathrm{C}$ treatment to approximately $28 \%$ in the $\mathrm{H}$, and only $8 \%$ in $\mathrm{H} 98$. The detailed work of Cohen et al. (2008) does not explain this fact completely. If we add a hypothetical third point to these series (zero velocity at the pith depth) and fit the proper functions, the $\mathrm{C}$ series fits better to a logarithmic pattern, whereas $\mathrm{H} 98$ fits better to a linear one. In studying the question of why trees growing on better sites showed greater sapwood permeability and conductance, Shelburne and Hedden (1996) obtained logarithmic and linear fits for poor and good sites, respectively. This changing pattern in the hydraulic conductivity of the sapwood could be explained by differences in permeability due to a higher functionality of tracheids. Better sites allow for additional 
functional tissue in the inner sapwood, which thus enhances the tree's ability to obtain adequate nutrients and water. In our case, the H98 trees had been growing in better site conditions for a longer period of time, and hence, their conductive anatomy was more adapted (the outer and inner thermocouples were located in rings formed after the 1998 thinning, i.e., under good site conditions), whereas the sapwood permeability drops off much more rapidly in the inner sapwood of trees growing in poor sites like the $\mathrm{C}$ treatment, because many tracheids have become non-functional. In contrast, the $H$ trees, showed intermediate pattern because, on the one hand, they are growing on a good site since 2008 and show higher permeability along the sapwood, but, on the other hand, they have had little time to adapt to the new site conditions, and the rings before 2008 were formed under poor site conditions due to excessive competence.

Second, the values of sap flow found in this work for 55-year-old P. halepensis trees ranged from 5 to 181 day $^{-1}$ which are consistent, in the case of the $\mathrm{H}$ treatment (basal area $9.4 \mathrm{~m}^{2} \mathrm{ha}^{-1}$ ), with those found in the same species and basal area by Schiller and Cohen (1998) under more arid Mediterranean conditions (maximum and average of 49 and 171 day $^{-1}$, respectively). A noticeable finding is that the larger H98 trees (diameter, crown volume, height, etc.) used less water than the smaller $H$ trees. This observation is not common in the literature, where the opposite pattern is usually reported (O'Grady et al. 1999). However, this difference is relatively low despite the higher differences in $v_{s}$ between both treatments. The reason for these observations again underscores the relative importance of the inner and outer sapwood in the total tree-water use for both treatments. The $\mathrm{H}$ is nearly exempted from water deficits year-round, thus exhibiting a type of water-spending behaviour indicative of the sudden release of water and nutrient resources. This observation is reflected in notably wide new rings (outer sapwood growth), high sap velocities and different response to vapour pressure deficit (Fig. 2 
Electronic supplemental material). In H98, a higher number and better functionality of tracheid layers in the inner sapwood allows for sufficient water supply to its dense and expanded crown, thus minimising the differences with $\mathrm{H}$, where the impact of previous branches and tissues is lower. However, this pattern is likely to change in the short term because the cool spells indicate no differences between them.

However, the results for stand transpiration give a different raking for the treatments to that obtained on a tree basis. Effectively, when the number of trees is taken into account, the $\mathrm{C}$ treatment is the most water-spending stand in spite of its lower growth. Low growth and high green water losses are the reasons to implement hydrologyoriented (proactive adaptive) silviculture. Transpiration values presented here are in the range of those reported for the species by Ungar et al. (2013), although the long-term average in our case is lower. This could be due to the cumulative effect of wet days in our case that led to a relative lower importance of days owning high evaporative demand (high VPD, see Table 2 and Fig. 1). Nevertheless, our data are subjected to errors. In addition to the errors associated with the heat pulse method for the $v_{s}$ estimation (Hatton et al. 1990), computation of the sap flow from $v_{s}$ may lead to important overestimations that have been widely reported and discussed in tree water use studies (Delzon et al. 2004; Cohen et al. 2008). We established a pattern of variation of $v_{s}$ with the area of the sapwood annuli sampled by each thermocouple (Hatton et al., 1990). In contrast, the results from Cohen et al. (2008) indicate that the pattern of $v_{s}$ in this species in Israel decreases considerably, with negligible values beyond a $4-\mathrm{cm}$ depth. This reasoning would make our values of sap flow to decrease. By contrast, applying the correction factor from Delzon et al. (2004) for maritime pines (a fastgrowing species in a more humid climate), our overall sap flow values would increase. Thus, it can be argued that our criteria can yield acceptable values, particularly if we 
consider that the years of study were particularly wet (the correction factor from the latter reference may be more appropriate).

Although the $\mathrm{H}$ trees transpired more water than $\mathrm{H} 98$, there was more water in the soil in the former than in the latter. The interception loss is a direct cause for this difference because net precipitation in $\mathrm{H}$ was approximately $10 \%$ higher. The elapsed time from thinning changed the tree storage capacity, as indicated by a difference of $0.82 \mathrm{~mm}$ between the intercepts (Rutter, 1963). The throughfall (49-62\% of rainfall) and stemflow $(0.25-0.5 \%$ of rainfall) values fall within the range reported in other studies conducted on isolated trees in the Mediterranean area (Belmonte Serrato 1997; Pereira et al. 2009). Another important difference between H98 and H (and extensively to the remaining treatments) is that found in the hydraulic properties of the soil, as field capacity (and absolute soil water content) was lower in H98. This could be due either to spatial variations in the sites (corroborated by the BAI chronology, Fig. 2, which indicated lower growth of H98 trees) or to the forest treatments themselves. If we assume the chronosequence hypothesis of this work (which establishes that both soils are similar), then it is needed to address why a lower water holding capacity have appeared in $\mathrm{H} 98$ after the thinning intervention. A possible explanation could derive from the higher density of root systems in the $\mathrm{H}$ treatment, which contribute (death or alive) substantially to soil organic matter (Persson 2012); their cavities can readily fill with water during and after major precipitation events, thus affecting soil hydraulic properties (Devitt and Smith 2002). This reasoning would mean that thinning from high to low densities might affect the soil water holding capacity in the mid term.

\subsection{Water balance}

Thinning has affected all the water cycle components considered in this study. The water balance indicates that the first main difference among treatments is found in the 
interception loss ( $\mathrm{C}$ intercepted $27 \%$ more rainfall than $\mathrm{H}$ ), as previously reported (Molina and del Campo 2012). Thinning also diminished the stand transpiration in all cases, although this reduction was lower than that found for rainfall interception (differences $<10 \%$ of rainfall). The important point here is that, in spite of the higher water use rates maintained in the remaining trees, the stand transpiration component is reduced even in the low intensity thinning treatment. Our results also indicate a little competence between transpiration and the deep infiltration terms for the throughfall water, as they present opposite seasonal patterns. This would mean that the differences in throughfall in wet-cool spells are relocated into deep infiltration water if the soil is wet enough; all the treatments presented important differences in this term against the control $(>12 \%)$. The term for soil/understory evaporation owns higher uncertainty due to its residual nature. This component yielded low differences among treatments $(<10 \%$ of rainfall), which would mean that, in spite of clearing vegetation, the evaporation is not severely increased. The ratio of the evaporation term to rainfall deduced in this work (0.24-0.33) is slightly lower to that reported by Ungar et al. (2013) in a drier climate (0.34-0.42). Thus, higher soil or understory evaporation in the more intensive treatments (M, H and H98) is compensated with reduced transpiration due to a lower tree number per unit area. Regarding the temporal evolution, water balance between $\mathrm{H}$ and $\mathrm{H} 98$ indicates that the latter evolves towards the values found for the medium intensity treatment, with similar cover but higher number of trees. Ten years after thinning primary and secondary growth have affected the entire tree architecture, including the crown densification and a higher complexity in canopy structure. However, our results would indicate that theses changes could be easily integrated into the forest cover metric, at least with regards their effects on the tree-water relationships. In fact, 
regressing the blue to green water ratio on the forest cover (proportion) the model yields a good fit $\left(r^{2}>0.96 ; p<0.01 ;\right.$ Fig. 3 Electronic supplemental material).

Concluding, we can confirm the two experimental hypotheses tested in this work and consider the results meaningful for a hydrology-oriented silviculture for these types of plantations. Methods from dendrochronology and hydrology have proven useful in deepening our understanding of the effects of thinning in this semiarid forest. The lack of forest management led to growth stagnation and to a higher and stronger dependence on climate fluctuations (rainfall variability), as was reflected by the BAIi. Management of these forests for maximising blue water budgets is effective both on the short and the mid-term according to the usual forestry timeframes. Ten years after thinning, tree growth and transpiration remained enhanced with higher relative inner sapwood permeability, providing evidence of the maintenance of a more effective sapwood area. However, there are important limitations in our results. First, due to the atypical wet years studied, this balance is expected to change drastically in drier years (Schiller and Cohen 1998; Ungar et al. 2013). Secondly, the residual evaporation term should be experimentally addressed in order to have a better estimation of errors associated with the global water balance. Thirdly, the vegetation structure of this site is quite simple, with little importance of the understory (even in the 1998 thinning, where scrub weeding is accomplished regularly) meaning that translating these results to other forest plantations need caution. This study has also identified some questions and relationships between the measured variables (e.g. transpiration and BAI, soil properties in H98) that require further evaluation and should be the subject of successive studies in drier years. In any case it is evident from our view the importance of these water-centred studies in the field of forest management. 


\section{Acknowledgements}

This study is a component of two research projects: "CGL2011-28776-C02-02, Hydrological characterisation of forest structures at plot scale for an adaptive management, HYDROSIL", funded by the Spanish Ministry of Science and Innovation and FEDER funds, and "Determination of hydrologic and forest recovery factors in Mediterranean forests and their social perception", led by Dr. E. Rojas and supported by the Ministry of Environment, Rural and Marine Affairs. The authors are grateful to the Valencia Regional Government (CMAAUV, Generalitat Valenciana) and the VAERSA staff for their support in allowing the use of the La Hunde experimental forest and for their assistance in carrying out the fieldwork. The second author thanks the Mundus 17 Program, coordinated by the University of Porto - Portugal.

\section{References}

Andréassian V (2004) Waters and forests: from historical controversy to scientific debate. J Hydrol 291:1-27. doi: 10.1016/j.jhydrol.2003.12.015

Aussenac G (2000) Interactions between forest stands and microclimate: Ecophysiological aspects and consequences for silviculture. Ann Sci 57:287-301.

Aussenac G, Granier A (1988) Effects of thinning on water stress and growth in Douglas-fir. Can J For Res 18:100-105. doi: 10.1139/x88-015

Belmonte Serrato F (1997) Interceptación en bosque y matorral mediterráneo semiárido: Balance hídrico y distribución espacial de la lluvia neta. Doctoral Thesis, Universidad de Murcia 
Birot Y, Gracia C (2011) Water for Forests and People in the Mediterranean Region: A Challenging Balance. European Forest Institute

Bunn AG (2008) A dendrochronology program library in R (dplR). Dendrochronologia 26:115-124. doi: 10.1016/j.dendro.2008.01.002

Burgess SSO, Adams MA, Turner NC, et al. (2001) An improved heat pulse method to measure low and reverse rates of sap flow in woody plants. Tree Physiol 21:589-598. doi: $10.1093 /$ treephys/21.9.589

Cohen Y, Cohen S, Cantuarias-Aviles T, Schiller G (2008) Variations in the radial gradient of sap velocity in trunks of forest and fruit trees. Plant Soil 305:49-59. doi: 10.1007/s11104-007-9351-0

Condés S, Sterba H (2008) Comparing an individual tree growth model for Pinus halepensis Mill. in the Spanish region of Murcia with yield tables gained from the same area. Eur J For Res 127:253-261. doi: 10.1007/s10342-007-0201-7

Cook ER, Briffa KR (1990) A comparison of some tree-ring standardization methods. Methods Dendrochronology Appl. Environ. Sci.

Del Campo AD (2013) Research resource review: Revisiting Experimental Catchment Studies in Forest Hydrology: Proceedings of a Workshop Held During the XXV IUGG General Assembly in Melbourne, Australia. Prog Phys Geog 37: 147-149. doi: $10.1177 / 0309133312465252$

Delzon S, Loustau D (2005) Age-related decline in stand water use: sap flow and transpiration in a pine forest chronosequence. Agric For Meteorol 129:105-119. doi: 10.1016/j.agrformet.2005.01.002 
Delzon S, Sartore M, Granier A, Loustau D (2004) Radial profiles of sap flow with increasing tree size in maritime pine. Tree Physiol 24:1285-1293. doi:

10.1093/treephys/24.11.1285

Devitt DA, Smith SD (2002) Root channel macropores enhance downward movement of water in a Mojave Desert ecosystem. J Arid Environ 50:99-108. doi:

10.1006/jare.2001.0853

Falkenmark M (2003) Freshwater as shared between society and ecosystems: from divided approaches to integrated challenges. Phil Trans R Soc B 358:2037-2049

FAO F and AO of the UN (2010) Global Forest Resources Assessment 2010: Main Report. Food and Agriculture Organization of the United Nations

Fitzgerald J, Jacobsen JB, Blennow K, et al. (2013) Climate change in European forests: how to adapt. European Forest Institute, Joensuu, Finland

Fritts H (1976) Tree Rings and Climate. Elsevier Science

Ganatsios HP, Tsioras PA, Pavlidis T (2010) Water yield changes as a result of silvicultural treatments in an oak ecosystem. For Ecol Manag 260:1367-1374. doi: 10.1016/j.foreco.2010.07.033

Giuggiola A, Bugmann H, Zingg A, et al. (2013) Reduction of stand density increases drought resistance in xeric Scots pine forests. For Ecol Manag 310:827-835. doi: 10.1016/j.foreco.2013.09.030

Granier A (1987) Evaluation of transpiration in a Douglas-fir stand by means of sap flow measurements. Tree Physiol 3:309-320. doi: 10.1093/treephys/3.4.309 
Hatton TJ, Catchpole EA, Vertessy RA (1990) Integration of sapflow velocity to estimate plant water use. Tree Physiol 6:201-209. doi: 10.1093/treephys/6.2.201

Holmes RL (1983) Computer-Assisted Quality Control in Tree-Ring Dating and Measurement. Tree-Ring Bull 1983:51-67.

Klein T, Shpringer I, Fikler B, et al. (2013) Relationships between stomatal regulation, water-use, and water-use efficiency of two coexisting key Mediterranean tree species. For Ecol Manag 302:34-42. doi: 10.1016/j.foreco.2013.03.044

Linares JC, Tíscar PA, Camarero JJ, et al. (2011) Tree growth decline on relict WesternMediterranean mountain forest: Causes and Impacts. For. Decline Causes Impacts Lindner M, Maroschek M, Netherer S, et al. (2010) Climate change impacts, adaptive capacity, and vulnerability of European forest ecosystems. Adapt For For Manag Chang Clim Sel Pap Conf “Adaptation For For Manag Chang Clim Emphas For Health Rev Sci Policies Pract Umeå Swed August 25-28 2008 259:698-709. doi: 10.1016/j.foreco.2009.09.023

De Luis M, Novak K, Čufar K, Raventós J (2009) Size mediated climate-growth relationships in Pinus halepensis and Pinus pinea. Trees 23:1065-1073. doi: $10.1007 / \mathrm{s} 00468-009-0349-5$ Major J (1951) A Functional, Factorial Approach to Plant Ecology. Ecology 32:392412. doi: $10.2307 / 1931718$

Martínez-Vilalta J, Piñol J, Beven K (2002) A hydraulic model to predict droughtinduced mortality in woody plants: an application to climate change in the Mediterranean. Ecol Model 155:127-147. doi: 10.1016/S0304-3800(02)00025-X 
Medhurst JL, Battaglia M, Beadle CL (2002) Measured and predicted changes in tree and stand water use following high-intensity thinning of an 8-year-old Eucalyptus nitens plantation. Tree Physiol 22:775-784. doi: 10.1093/treephys/22.11.775

\section{Meko D, Stockton CW, Boggess WR (1995) THE TREE-RING RECORD OF}

SEVERE SUSTAINED DROUGHT1. JAWRA J Am Water Resour Assoc 31:789-801. doi: 10.1111/j.1752-1688.1995.tb03401.x

Mérian P, Pierrat J-C, Lebourgeois F (2013) Effect of sampling effort on the regional chronology statistics and climate-growth relationships estimation. Dendrochronologia 31:58-67. doi: 10.1016/j.dendro.2012.07.001

Molina AJ, del Campo AD (2012) The effects of experimental thinning on throughfall and stemflow: A contribution towards hydrology-oriented silviculture in Aleppo pine plantations. For Ecol Manag 269:206-213. doi: 10.1016/j.foreco.2011.12.037

Montero G, Cañellas I, Ruíz-Peinado R (2001) Growth and yield models for Pinus halepensis Mill. Rev Investig Agrar Sist Recur For 10:179-201.

Morikawa Y, Hattori S, Kiyono Y (1986) Transpiration of a 31-year-old Chamaecyparis obtusa Endl. stand before and after thinning. Tree Physiol 2:105-114. doi:

10.1093/treephys/2.1-2-3.105

O’Grady AP, Eamus D, Hutley LB (1999) Transpiration increases during the dry season: patterns of tree water use in eucalypt open-forests of northern Australia. Tree Physiol 19:591-597. doi: 10.1093/treephys/19.9.591

Pereira FL, Gash JHC, David JS, Valente F (2009) Evaporation of intercepted rainfall from isolated evergreen oak trees: Do the crowns behave as wet bulbs? Agric For Meteorol 149:667-679. doi: 10.1016/j.agrformet.2008.10.013 
Persson HA (2012) The High Input of Soil Organic Matter from Dead Tree Fine Roots into the Forest Soil. Int J For Res 2012:9.

Planchon O, Dubreuil V, Bernard V, Blain S (2008) Contribution of tree-ring analysis to the study of droughts in northwestern France (XIX-XXth century). Clim Past Discuss $4: 249-270$.

R Core Team (2013) R: A language and environment for statistical computing. $\mathrm{R}$ Foundation for Statistical Computing, Vienna, Austria

Raventós J, De Luís M, Gras MJ, et al. (2001) Growth of Pinus pinea and Pinus halepensis as affected by dryness, marine spray and land use changes in a Mediterranean semiarid ecosystem. Dendrochronologia 19:211-220.

Rutter AJ (1963) Studies in the Water Relations of Pinus Sylvestris in Plantation Conditions I. Measurements of Rainfall and Interception. J Ecol 51:191-203. doi: $10.2307 / 2257513$

Sánchez-Salguero R, Navarro RM, Camarero JJ, Fernández-Cancio Á (2010) Droughtinduced growth decline of Aleppo and maritime pine forests in south-eastern Spain. For. Syst. Vol 19 No 32010

Sarris D, Christodoulakis D, Körner C (2011) Impact of recent climatic change on growth of low elevation eastern Mediterranean forest trees. Clim Change 106:203-223. doi: 10.1007/s10584-010-9901-y

Sarris D, CHRISTODOULAKIS D, KÖRNER C (2007) Recent decline in precipitation and tree growth in the eastern Mediterranean. Glob Change Biol 13:1187-1200. doi: $10.1111 / \mathrm{j} .1365-2486.2007 .01348 . x$ 
Schiller G, Cohen Y (1998) Water balance of Pinus halepensis Mill. afforestation in an arid region. For Ecol Manag 105:121-128. doi: 10.1016/S0378-1127(97)00283-1

Shelburne VB, Hedden RL (1996) Effect of stem height, dominance class, and site quality on sapwood permeability in loblolly pine, (Pinus taeda L.). For Ecol Manag 83:163-169. doi: 10.1016/0378-1127(96)03727-9

Steel RGD, Torrie JH (1989) Bioestadística: principios y procedimientos. McGraw-Hill Ungar ED, Rotenberg E, Raz-Yaseef N, et al. (2013) Transpiration and annual water balance of Aleppo pine in a semiarid region: Implications for forest management. For Ecol Manag 298:39-51. doi: 10.1016/j.foreco.2013.03.003

Webb AA, Kathuria A, Turner L (2012) Longer-term changes in streamflow following logging and mixed species eucalypt forest regeneration: The Karuah experiment. J Hydrol 464-465:412-422. doi: 10.1016/j.jhydrol.2012.07.034

White D, Beadle C, Worledge D, et al. (1998) The influence of drought on the relationship between leaf and conducting sapwood area in Eucalyptus globulus and Eucalyptus nitens. Trees 12:406-414. doi: 10.1007/PL00009724 


\section{Figure captions}

Fig. 1 Meteorological conditions during the study period expressed as accumulated daily values for precipitation and mean daily values for the other variables: $\mathrm{Gr}$ is daily rainfall, $\mathrm{T}$ is the mean daily temperature of the air, and VPD is the mean daily vapour pressure deficit of the air

Fig. 2 Mean Basal Area Increment (BAI) values in each treatment along the entire growth period analysed (1960-2010, a) and a close-up (b) showing differences in growth after thinning in 1998 (H98) and in 2008 (remaining treatments). C: control, L: low intensity; M: medium intensity; H: high intensity 2008; H98: high intensity 1998

Fig. 3 Mean Basal Area Increment index (BAIi) in each treatment along the entire growth period analysed (1960-2010). Horizontal lines delimitate the 10-90\% range. C: control, L: low intensity; M: medium intensity; H: high intensity 2008; H98: high intensity 1998

Fig. 4 Daily mean accumulated values of transpiration $(\mathrm{mm})$ in each treatment along the entire study period (March 2009-May 2011). C: control, L: low intensity; M: medium intensity; H: high intensity 2008; H98: high intensity 1998

Fig. 5 Daily mean values of soil water content, expressed as its proportion over field capacity $(\mathrm{SWC} / \mathrm{FC})$, and deep infiltration $\left(\mathrm{I}_{>30 \mathrm{~cm}}\right)$ in each treatment along the entire study period (March 2009-May 2011). C: control, L: low intensity; M: medium intensity; H: high intensity 2008; H98: high intensity 1998 
Fig. 6 Relationship between throughfall $(\mathrm{mm})$ and rainfall $(\mathrm{mm})$ in the high intensity treatments ( $\mathrm{H}$ and $\mathrm{H} 98) . \mathrm{N}=28$ and 27 for $\mathrm{H}$ and $\mathrm{H} 98$ respectively. Regressions models were statistically significant at $p$-value $<0.001$. Statistical comparisons between the models indicated that intercepts were different at $p=0.001$. 


\section{ELECTRONIC SUPPLEMENTAL MATERIAL}

Fig. 1 Mean and standard deviation values of tree stemflow (l) and rainfall (mm) in the different spells studied for this variable.

Fig. 2 Mean daily values of sap flow velocity $\left(\mathrm{cm} \mathrm{h}^{-1}\right)$ as a function of the mean daily values of VPD $(\mathrm{KPa})$ for each treatment

Fig. 3 Relationship between the blue to green water ratio $(B / G)$ and forest cover (proportion). $\mathrm{N}=5$. The model was statistically significant at $\mathrm{p}$-value $<0.01$. 
$\mathrm{mm},{ }^{\circ} \mathrm{C}$

$\frac{7}{6}$
$\stackrel{0}{0}$
$\stackrel{0}{\rightarrow}$

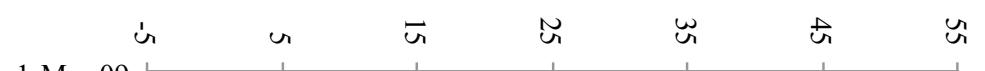

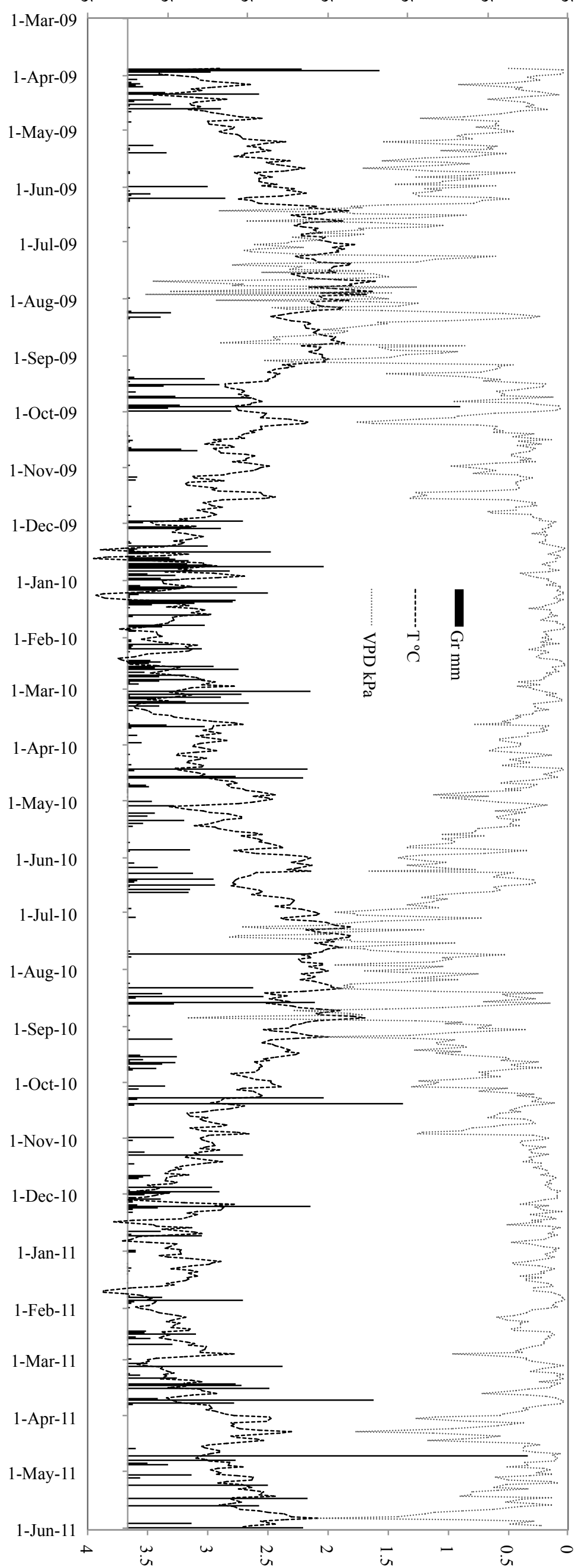




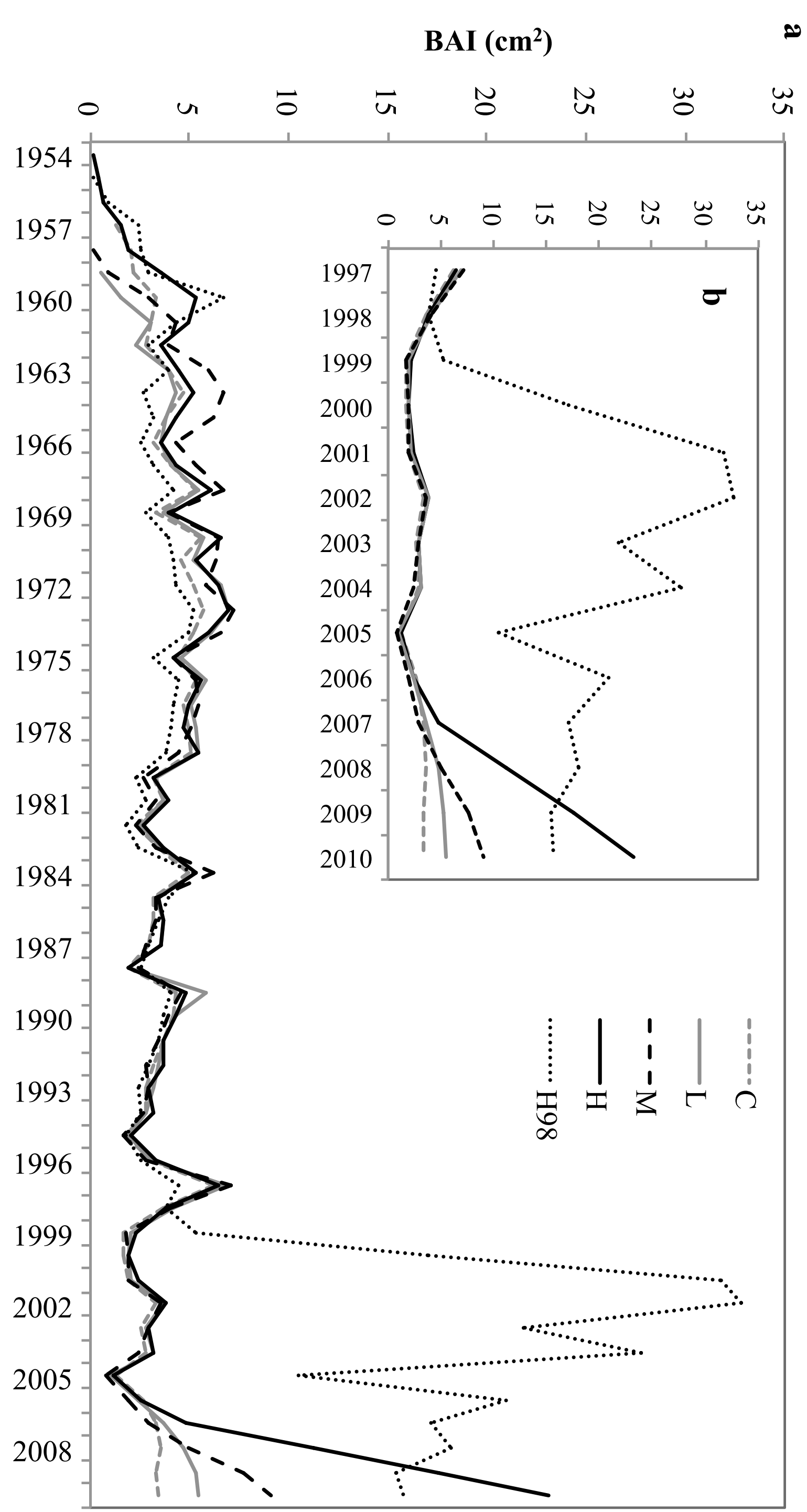



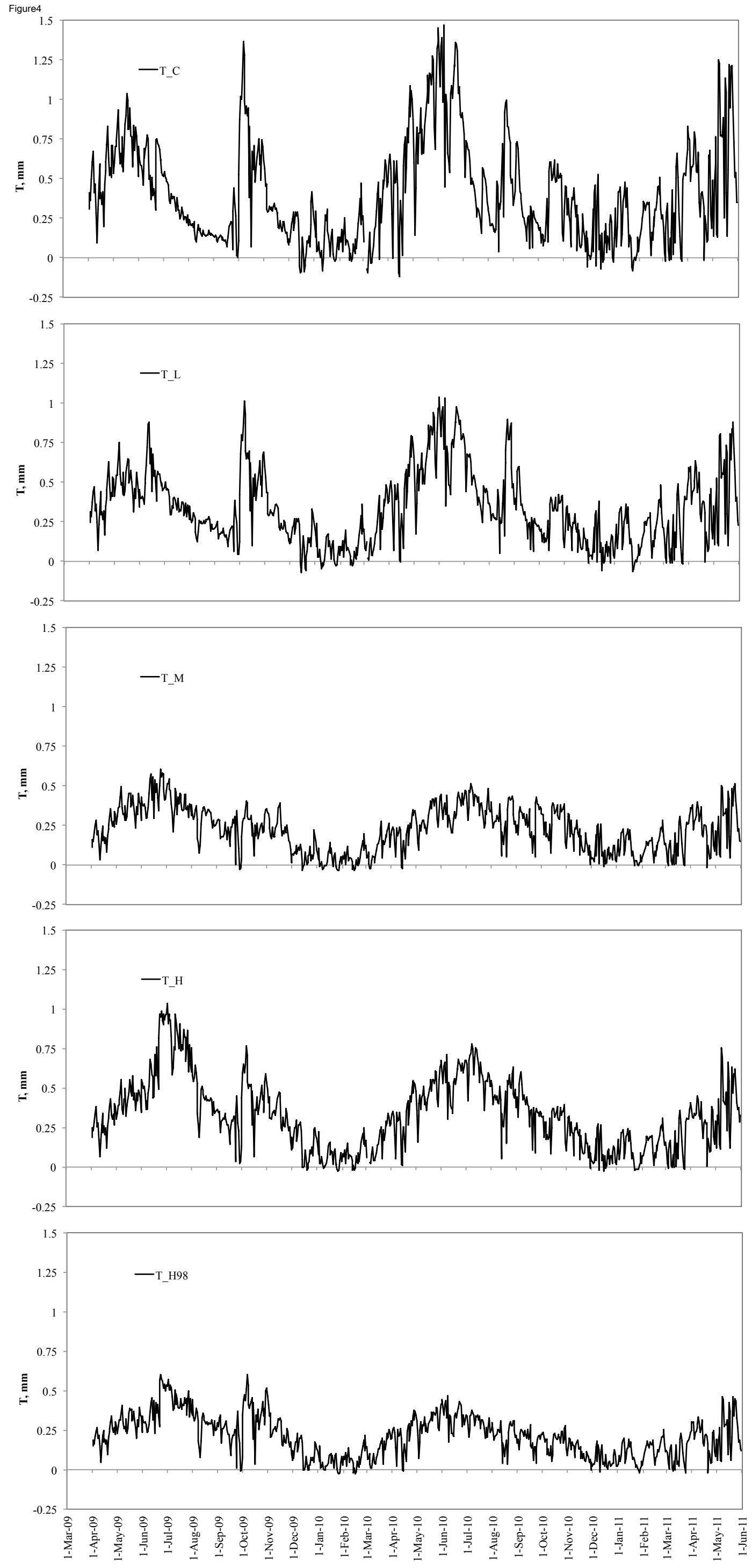
Figure6

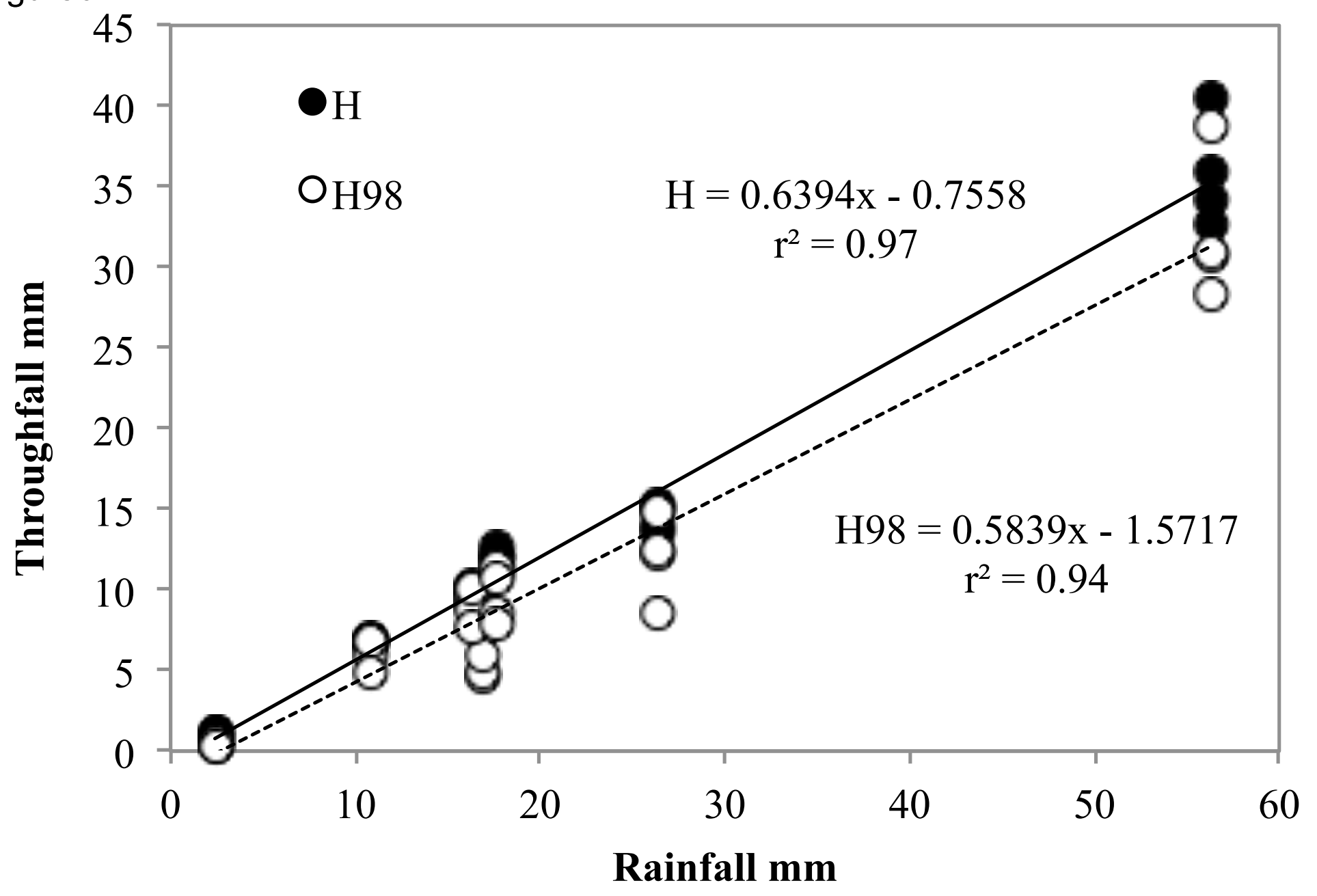


Table 1 Means of the forest-structure variables in the control and thinned (2008 and 1998) plots. H98 is the plot thinned in 1998; the rest thinned in 2008, except the control plot. DBH, diameter at breast height, is estimated from two wood cores (south and north) at a height of $1.3 \mathrm{~m}$. Adapted from Molina and del Campo (2012)

\begin{tabular}{|c|c|c|c|c|c|c|c|c|c|}
\hline $\begin{array}{l}\text { Thinning } \\
\text { Treatment }\end{array}$ & \begin{tabular}{|c|} 
Cover \\
$(\%)$
\end{tabular} & $\begin{array}{c}\text { Density } \\
\left(\text { trees } \mathrm{ha}^{-1}\right)\end{array}$ & $\begin{array}{l}\text { DBH } \\
(\mathrm{cm})\end{array}$ & $\begin{array}{c}\mathrm{LAI}\left(\mathrm{m}^{2}\right. \\
\left.\mathrm{m}^{-2}\right)\end{array}$ & $\begin{array}{l}\text { Hei } \\
\text { ght } \\
\text { (m) }\end{array}$ & $\begin{array}{l}\text { Heart } \\
\text { wood } \\
\text { area } \\
\left(\mathrm{cm}^{2}\right)\end{array}$ & $\begin{array}{l}\text { Sapw } \\
\text { ood } \\
\text { area } \\
\left(\mathrm{cm}^{2}\right)\end{array}$ & $\begin{array}{c}\text { Crow } \\
\mathrm{n} \\
\text { proje } \\
\text { cted } \\
\text { area } \\
\left(\mathrm{m}^{2}\right)\end{array}$ & $\begin{array}{l}\text { Cro } \\
\text { wn } \\
\text { volu } \\
\text { me } \\
\left(\mathrm{m}^{3}\right)\end{array}$ \\
\hline Control (C) & 84 & 1489 & 16.9 & 2.6 & 11.5 & 0.58 & 230.9 & & \\
\hline $\begin{array}{l}\text { Low intensity } \\
\text { (L) }\end{array}$ & 68 & 744 & 17.7 & 1.7 & 12.2 & 0.32 & 256.3 & & \\
\hline $\begin{array}{l}\text { Medium } \\
\text { intensity (M) }\end{array}$ & 50 & 478 & 17.5 & 1.7 & 11.3 & 0.25 & 250.8 & & \\
\hline $\begin{array}{l}\text { High intensity } \\
(\mathrm{H})\end{array}$ & 22 & 178 & 20.4 & 0.5 & 12.2 & 3.9 & 332.0 & 15.6 & 53.4 \\
\hline $\begin{array}{l}\text { High intensity- } \\
1998 \text { (H98) }\end{array}$ & 41 & 155 & 25.2 & 0.9 & 12.6 & 8.8 & 504.7 & 25.8 & 93.8 \\
\hline
\end{tabular}


Table 2 Mean values of daily $\mathrm{v}_{\mathrm{s}}\left(\mathrm{cm} \mathrm{h}^{-1}\right)$, accumulated daily sap flow $\left(1\right.$ day $\left.^{-1}\right)$ and daily soil water content relative to field capacity $\left(\mathrm{SWC} / \mathrm{FC}, \mathrm{cm}^{3} \mathrm{~cm}^{-3}\right)$ as regards the four day-types considered in this study (DC, dry-cool; DW, dry-warm; WC, wet-cool; WW, wet-warm) and the sapwood depth (the case of $\mathrm{v}_{\mathrm{s}}$ ). Different letters in a same row indicate significant differences at $p$-value $<0.05$ in that variable for that level of the factor. In the H98 column, * indicates significant differences with the $\mathrm{H}$ treatment at $\mathrm{p}$-value $<0.05$.

\begin{tabular}{|l|l|l|l|l|l|}
\hline $\begin{array}{l}\text { Variable } \\
\text { and factor }\end{array}$ & $\mathbf{C}$ & $\mathbf{L}$ & $\mathbf{M}$ & $\mathbf{H}$ & $\mathbf{H 9 8}$ \\
\hline $\mathbf{v}_{\mathbf{s}}\left(\mathbf{c m ~ h}^{-\mathbf{1}}\right)$ & & & & & \\
\hline Outer & $1.18 \mathrm{a}$ & $1.26 \mathrm{~b}$ & $1.45 \mathrm{c}$ & $3.46 \mathrm{~d}$ & $1.79^{*}$ \\
\hline Inner & $0.70 \mathrm{a}$ & $0.88 \mathrm{~b}$ & $0.94 \mathrm{~b}$ & $2.66 \mathrm{c}$ & $1.64^{*}$ \\
\hline DC $(8.7 \%)$ & $0.71 \mathrm{a}$ & $0.78 \mathrm{ab}$ & $0.93 \mathrm{~b}$ & $1.98 \mathrm{c}$ & $1.43^{*}$ \\
\hline DW $(17.7 \%)$ & $0.94 \mathrm{a}$ & $1.24 \mathrm{~b}$ & $2.29 \mathrm{c}$ & $5.59 \mathrm{~d}$ & $2.58^{*}$ \\
\hline WC $(43.1 \%)$ & $0.64 \mathrm{a}$ & $0.66 \mathrm{a}$ & $1.03 \mathrm{~b}$ & $1.54 \mathrm{c}$ & $0.87^{*}$ \\
\hline WW $(30.4 \%)$ & $1.42 \mathrm{a}$ & $1.62 \mathrm{~b}$ & $2.62 \mathrm{c}$ & $4.00 \mathrm{~d}$ & $2.07^{*}$ \\
\hline $\begin{array}{l}\text { Sap flow(l } \\
\text { day-1) }\end{array}$ & & & & & \\
\hline DC & $3.57 \mathrm{a}$ & $3.82 \mathrm{a}$ & $4.54 \mathrm{a}$ & $12.00 \mathrm{~b}$ & 12.9 \\
\hline DW & $4.58 \mathrm{a}$ & $6.51 \mathrm{~b}$ & $11.33 \mathrm{c}$ & $33.80 \mathrm{~d}$ & $22.90^{*}$ \\
\hline WC & $2.72 \mathrm{a}$ & $2.70 \mathrm{a}$ & $5.08 \mathrm{~b}$ & $7.94 \mathrm{c}$ & 8.03 \\
\hline WW & $6.89 \mathrm{a}$ & $8.00 \mathrm{a}$ & $12.93 \mathrm{~b}$ & $24.08 \mathrm{c}$ & $18.94^{*}$ \\
\hline SWC/FC & & & & & \\
\hline DC & $0.66 \mathrm{a}$ & $0.61 \mathrm{a}$ & $0.78 \mathrm{~b}$ & $0.81 \mathrm{~b}$ & $0.70^{*}$ \\
\hline DW & $0.49 \mathrm{a}$ & $0.44 \mathrm{a}$ & $0.62 \mathrm{~b}$ & $0.67 \mathrm{~b}$ & $0.59^{*}$ \\
\hline WC & $0.84 \mathrm{a}$ & $0.86 \mathrm{a}$ & $0.83 \mathrm{a}$ & $0.96 \mathrm{~b}$ & $0.89^{*}$ \\
\hline WW & $0.67 \mathrm{a}$ & $0.69 \mathrm{a}$ & $0.75 \mathrm{ab}$ & $0.82 \mathrm{~b}$ & $0.71^{*}$ \\
\hline
\end{tabular}


Table 3 Pearson correlation coefficients (only high significant cases with pvalue $<0.001$ are shown) between tree growth (Basal Area Increment, BAI) and different transpiration variables (sap flow velocity $v_{s}$ and sap flow), as regards the study year (2009 and 2010) and the day-type (DC, dry-cool; DW, dry-warm; WC, wet-cool; WW, wet-warm). N=20.

\begin{tabular}{|c|c|c|}
\hline & BAI 09 & BAI10 \\
\hline Sap flow_09 & 0.736 & 0.763 \\
\hline Sap flow_09_DC & 0.765 & 0.78 \\
\hline Sap flow_09_DW & 0.785 & 0.82 \\
\hline Sap flow_09_WC & 0.727 & 0.747 \\
\hline Sap flow_09_WW & 0.751 & 0.761 \\
\hline Sap flow_10_DW & 0.725 & 0.736 \\
\hline Sap flow_10_WW & 0.679 & 0.684 \\
\hline$v_{s_{-}}$inner_09 & 0.752 & 0.835 \\
\hline$v_{s_{-}}$inner_10 & & 0.74 \\
\hline$v_{s_{-}}$outer_09 & & 0.807 \\
\hline$v_{s \_}$inner_09_DC & 0.733 & 0.81 \\
\hline$v_{s_{-}}$inner_09_DW & 0.764 & 0.849 \\
\hline 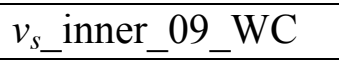 & & 0.76 \\
\hline$v_{s_{-}}$inner_09_WW & 0.727 & 0.804 \\
\hline$v_{s_{-}}$outer_09_DC & & 0.81 \\
\hline$v_{s \_}$outer_09_DW & & 0.817 \\
\hline$v_{s \_}$outer_09_WC & & 0.745 \\
\hline$v_{s_{-}}$outer_09_WW & & 0.781 \\
\hline$v_{s_{-}}$inner_10_DC & & 0.677 \\
\hline$v_{s \_}$inner_10_DW & 0.709 & 0.785 \\
\hline$v_{s}$ inner_10_WW & & 0.704 \\
\hline$v_{s \_}$outer_10_DW & & 0.719 \\
\hline
\end{tabular}


Table 4 Itemisation of the water cycle at the stand scale for the whole study spell (March 2009 to May 2011) for each treatment (C: control, L: low intensity; M: medium intensity; H: high intensity 2008; H98: high intensity 1998). Gr: gross rainfall; It: interception loss; Thr: throughfall; $\mathrm{T}$ : stand transpiration; $\mathrm{I}_{30 \mathrm{~cm}}$ : deep infiltration; E: evaporation from soil, litterfall and grass/scrub transpiration. ET total: summing up of the evapotranspiration terms; B/G: blue (deep infiltration) to green (total evapotranspiration) ratio. See text for details.

\begin{tabular}{|c|c|c|c|c|c|c|c|c|}
\hline & Gr & It & Thr & $\mathbf{T}$ & $\mathbf{I}_{>30 \mathrm{~cm}}$ & $\mathbf{E}$ & $\begin{array}{c}\text { ET } \\
\text { total }\end{array}$ & $\mathrm{B} / \mathrm{G}$ \\
\hline \multicolumn{9}{|l|}{$\mathbf{m m}$} \\
\hline C & 1545 & 611.8 & 933.2 & 319.8 & 207.0 & 406.3 & 1338.0 & 0.155 \\
\hline $\mathbf{H}$ & 1545 & 191.6 & 1353.4 & 261.1 & 647.4 & 445.0 & 897.6 & 0.721 \\
\hline H98 & 1545 & 419.5 & 1125.5 & 168.4 & 499.5 & 457.6 & 1045.5 & 0.478 \\
\hline $\mathbf{L}$ & 1545 & 517.6 & 1027.4 & 264.2 & 395.5 & 367.7 & 1149.5 & 0.344 \\
\hline $\mathbf{M}$ & 1545 & 400.2 & 1144.8 & 180.8 & 455.8 & 508.3 & 1089.2 & 0.418 \\
\hline \multicolumn{9}{|c|}{$\%$} \\
\hline C & 100 & 39.6 & 60.4 & 20.7 & 13.4 & 26.3 & 86.6 & 0.155 \\
\hline $\mathbf{H}$ & 100 & 12.4 & 87.6 & 16.9 & 41.9 & 28.8 & 58.1 & 0.721 \\
\hline H98 & 100 & 27.1 & 72.8 & 10.9 & 32.3 & 29.6 & 67.7 & 0.478 \\
\hline $\mathbf{L}$ & 100 & 33.5 & 66.5 & 17.1 & 25.6 & 23.8 & 74.4 & 0.344 \\
\hline $\mathbf{M}$ & 100 & 25.9 & 74.1 & 11.7 & 29.5 & 32.9 & 70.5 & 0.418 \\
\hline & & & & & & & & \\
\hline
\end{tabular}



Electfonic Supplementary Material_fig1

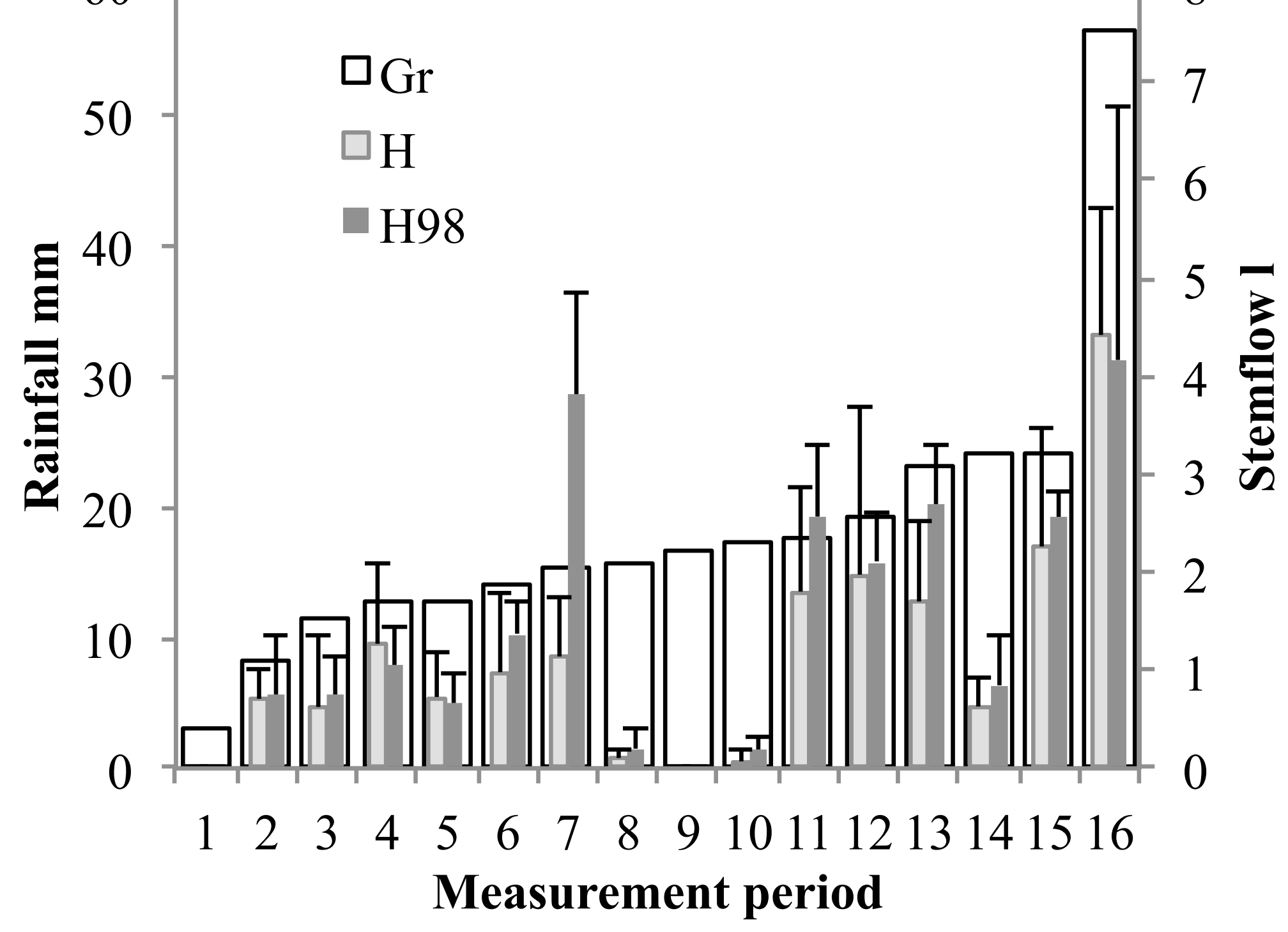



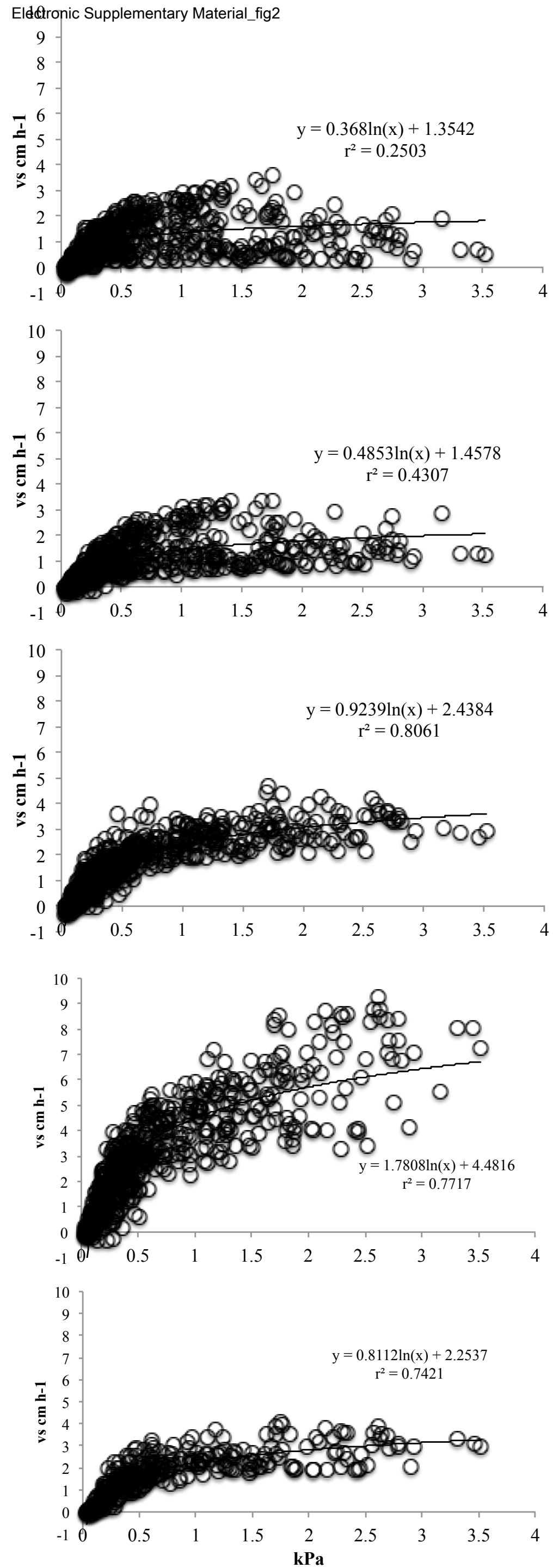
Electronic Supplementary Material_fig3

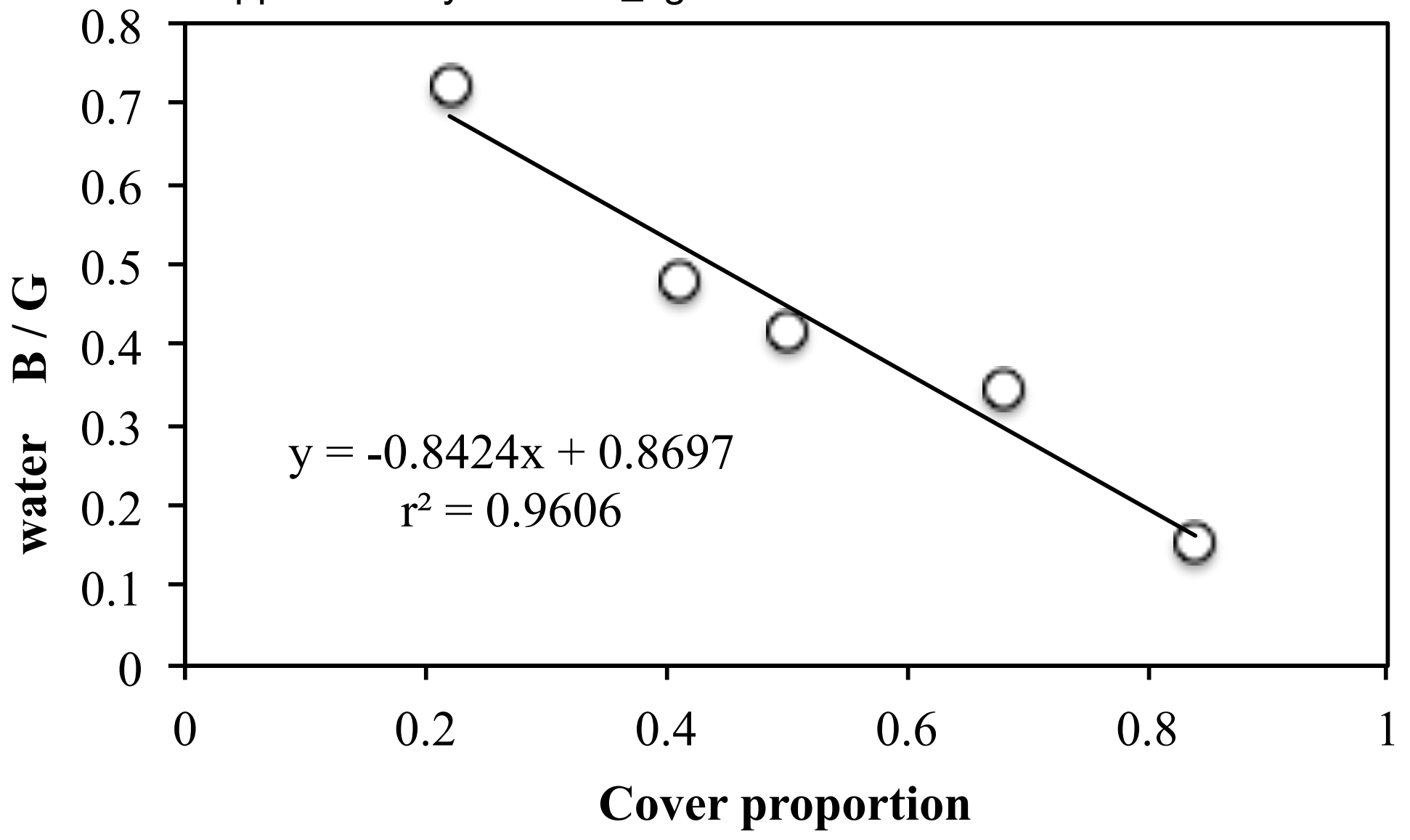

